\title{
A Review of the Incidence and Consequences of Cigarette Filter Vent Blocking Among Smokers*
}

\author{
by \\ Richard R. Baker ${ }^{1}$ and Leslie S. Lewis ${ }^{2}$ \\ ${ }^{1}$ British American Tobacco, RED Centre, Southampton, UK and \\ ${ }^{2}$ R.J. Reynolds Tobacco Company, Research E Development, Winston-Salem, NC, USA.
}

\section{CONTENTS}

Summary

Zusammenfassung

Résumé

Introduction

Section 1. Measurements of incidence of filter vent blocking

1.1 Measurement by filter 'tar' stain technique

1.2 Consideration of filter stain patterns

1.3 Data from interviews with smokers

1.4 Video-taped observations

1.5 Mouth insertion depths studies

Section 2. Effects of vent blocking on cigarette ventilation and machine smoke yields

Section 3. Effect of experimentally blocking filter vents on buman smoke yields

3.1 Studies where subjects are cued to smoke the blocked cigarette to a given puffing regimen

3.2 Studies in which the subjects smoked ad libitum

Section 4. Simultaneous determination of incidence of vent blocking and smoke yields under ad libitum human smoking conditions

Conclusions

Acknowledgments

References

\section{SUMMARY}

Vent blocking, the covering of the filter ventilation zone on a cigarette during smoking, is a potentially important aspect of smoking behavior. Various techniques have been used to assess the incidence of vent blocking, and widely different views have been expressed on its impor- tance. Studies relevant to filter vent blocking have been reviewed with two overall objectives: to examine critically the evidence on the occurrence of vent blocking and to assess the effects of vent blocking on the smoke yield to the smoker. The reviewed studies fall into four main categories: (1) measurements of the incidence of filter vent blocking among smokers; (2) the observed effects of vent blocking on cigarette ventilation and machine smoke yields; (3) the effect of experimentally blocking vents on buman smoke yields; and (4) simultaneous determination of vent blocking and smoke yield under human smoking conditions.

Direct observation indicates that only $4 \%$ of smokers have their fingers in direct contact with the cigarette during puffing. Estimates of vent blocking incidence by lips during smoking range from $15-24 \%$ (saliva-staining technique) to up to $50 \%$ ('tar' staining pattern technique) of smokers. For those smokers who do block the ventilation zone, a mean of $27 \%$ of the vents are blocked, and a maximum of about $50 \%$.

When the cigarettes are machine-smoked, the smoke yield increases in a highly non-linear manner as the blocked portion of the filter ventilation zone increases. This effect is also more pronounced at higher original filter ventilation levels. In contrast, smoking behavior monitoring techniques have shown that when the experimenter deliberately blocks the vent zone, the human smoker adjusts by taking smaller and fewer puffs. The blocked filter affects the yields of smoke components to the smoker less than it does smoking-machine measured yields.

It is concluded that the incidence of vent zone blocking by fingers is quite low and relatively insignificant. The most reliable estimate for lip blocking is that up to $25 \%$ of smokers may cover the vent zone during at least one puff and for most smokers the coverage is partial. Ventila- 
tion zone blocking as it occurs in practice has only a relatively minor effect on human smoke yields compared to other smoker behavior factors. When a human smoker inadvertently partially or completely blocks the filter ventilation zone during smoking, he/she adjusts by taking smaller and fewer puffs. Because of these changes in puffing behavior during human smoking, predictions of the effects of filter vent blocking on smoke yields based solely on smoking machine yields are deceptive. [Beitr. Tabakforsch. Int. 19 (2000) 209-228]

\section{ZUSAMMENFASSUNG}

Das Abdecken der Filterventilationslöcher einer Cigarette während des Rauchens ist ein potentiell wichtiger Aspekt des Rauchverhaltens. Mit Hilfe verschiedene Techniken wurde die Häufigkeit des Abdeckens der Ventilationslöcher bestimmt, und stark voneinander abweichende Ansichten wurden bezüglich der Bedeutung dieses Aspekts vertreten. Literatur zu diesem Thema wurde in Bezug auf zwei generelle Fragestellungen bewertet: kritische Untersuchung der Häufigkeit des Blockierens der Filterventilationslöcher und Erfassung der Auswirkungen auf die Aufnahme von Rauchinhaltsstoffen durch den Raucher. Die untersuchten Studien lassen sich in vier Kategorien unterteilen: 1) Messungen zur Häufigkeit des Abdeckens der Filterventilationslöcher bei Rauchern; 2) die beobachteten Auswirkungen des Abdeckens des Ventilationsbereichs auf die Cigarettenventilation und die Rauchausbeute beim maschinellen Abrauchen der Cigaretten; 3) die Auswirkungen des experimentellen Abdeckens der Ventilationslöcher auf die Rauchausbeute beim Raucher; 4) die gleichzeitige Untersuchung der Abdeckung der Ventilationslöcher und der Rauchausbeute unter den Bedingungen des menschlichen Rauchverhaltens.

Direkte Beobachtungen zeigen, dass nur 4\% der Raucher ihre Finger während des Zuges in Kontakt mit der Cigarette haben. Schätzungen über ein Abdecken der Ventilationszone durch die Lippen des Rauchers während des Rauchens liegen bei $15 \%$ bis $24 \%$ (Nachweis durch Sichtbarmachen des Speichelabdrucks) und reichen bis 50\% (Nachweis durch Kondensatfärbemethode). Bei Rauchern, die die Ventilationszone abdecken, sind durchschnittlich $27 \%$ und maximal $50 \%$ der Ventilationslöcher abgedeckt.

Beim Abrauchen mit einer Rauchmaschine erhöht sich die Rauchausbeute in einem deutlich nicht linearem Maße, wenn der abgedeckte Bereich der Filterventilationszone zunimmt. Dieser Effekt ist bei Cigaretten mit ursprünglich stärkerer Filterventilation deutlicher ausgeprägt. Im Gegensatz hierzu haben Untersuchungen gezeigt, dass der Raucher sein Rauchverhalten anpaßt und kleinere sowie weniger Züge nimmt, wenn der Experimentator bewusst die Ventilationszone abdeckt. Das Abdecken des Ventilationsbereichs hat geringere Auswirkungen auf die Aufnahme an Inhaltsstoffen durch den
Raucher als auf die Rauchausbeute beim Abrauchen von Cigaretten mit einer Rauchmaschine.

Es wird die Schlußfolgerung gezogen, dass das Abdecken der Filterventilationslöcher durch die Finger recht selten vorkommt und relativ unbedeutend ist. Die verläßlichste Schätzung der Abdeckung der Ventilationszone durch die Lippen ist, dass bis zu 25\% der Raucher die Ventilationszone bei mindestens einem Zug vollständig und die meisten dieser Raucher die Ventilationszone jedoch nur teilweise abdecken. Das Abdecken der Ventilationslöcher, wie es tatsächlich auftritt, hat im Vergleich zu anderen Faktoren des Rauchverhaltens nur eine relativ geringe Auswirkung auf die Aufnahme von Inhaltsstoffen durch den Raucher. Wenn ein Raucher während des Rauchens unbeabsichtigt teilweise oder vollständig die Filterventilationszone abdeckt, paßt er sein Rauchverhalten durch kleinere und weniger Züge an. Wegen dieser Anpassungen sind Vorhersagen über die Auswirkungen der Abdeckung der Ventilationslöcher auf den Raucher, die nur auf der Rauchausbeute beim Abrauchen mit einer Rauchmaschine basieren, irreführend. [Beitr. Tabakforsch. Int. 19 (2000) 209-228]

\section{RESUME}

L'obstruction des trous de ventilation d'une cigarette en cours de combustion est un aspect particulièrement important du comportement au cours du fumage. Diverses techniques ont été appliquées pour évaluer la fréquence de l'obstruction des orifices, et des avis très divergents sur l'importance de cet aspect ont été exprimés. Cette communication passe en revue la littérature publiée sur l'obstruction et l'examine avec deux objectifs principaux: examiner de manière critique l'évidence de l'obstruction des orifices et évaluer les effets de l'obstruction sur le rendement des composants de la fumée recueillis par le fumeur. Les études passées en revue peuvent être réparties en quatre catégories: 1) détermination de la fréquence de l'obstruction des trous de ventilation par les fumeurs; 2) effets de l'obstruction sur la ventilation des cigarettes et le rendement de la fumée après fumage mécanique; 3) effets de l'obstruction expérimentale sur le rendement de la fumée après fumage bumain; et 4) détermination simultanée de l'obstruction des trous de ventilation et des rendements de la fumée dans les conditions de fumage humain.

L'observation directe indique que $4 \%$ seulement des fumeurs ont leurs doigts directement sur la cigarette pendant les bouffées. Les estimations de l'incidence de l'obstruction des orifices par les lèvres pendant les bouffées peuvent varier de 15 à $24 \%$ (visualisation des traces de salive) jusqu'à $50 \%$ (technique de coloration des traces de goudron) des fumeurs. Chez les fumeurs qui couvrent les orifices, une moyenne de $27 \%$ des trous de ventilation sont obstrués, et $50 \%$ au maximum.

Après fumage sur machine, le rendement de la fumée de cigarette accroit fortement d'une façon non linéaire, tant 
que la partie de la zone de ventilation obstruée augmente. Cet effet est également plus prononcé dans le cas d'un niveau initial de ventilation plus important. Par contre, les techniques de contrôle du comportement au fumage ont montré que si l'expérimentateur obstrue délibérément les trous de ventilation, le fumeur compense en prenant des bouffées plus légères et plus nombreuses. Après fumage humain, l'influence de l'obstruction des orifices sur les composants de la fumée absorbés par le fumeur est moins importante qu'après fumage sur machine.

On aboutit à la conclusion que l'incidence de l'obstruction des trous de ventilation par les doigts est rare et relativement insignifiante. L'estimation la plus fiable de l'obstruction par les lèvres est que $25 \%$ des fumeurs pourraient pendant au moins une bouffée couvrir les orifices de ventilation et que chez la plupart de ces fumeurs l'obstruction des orifices est partielle. L'obstruction des orifices, telle qu'elle apparait, a seulement un effet mineur sur les rendements des composants de la fumée absorbés par les fumeurs comparée à d'autres aspects du comportement au fumage. Si un fumeur couvre accidentellement une partie ou la totalité des orifices pendant les bouffées, il compense en prenant des bouffées plus légères et plus nombreuses. A cause de ces compensations, les prédictions des effets de l'obstruction des orifices sur les fumeurs, basées seulement sur les rendements des composants de la fumée après fumage sur machine, sont peu fiables. [Beitr. Tabakforsch. Int. 19 (2000) 209-200]

\section{INTRODUCTION}

SCHERER (48) has recently reviewed the literature on human smoking behavior and compensation. His review covered only briefly the incidence of filter vent zone blocking by smokers and it is this aspect of human smoking behavior that is the subject of the present review.

Filter ventilated cigarettes have been available for over thirty years and were developed to reduce the yields of all mainstream smoke components. In addition to diluting the smoke, filter ventilation affects several mechanisms that are important in smoke generation, including the combustion processes, filtration of the smoke aerosol particles and gaseous diffusion. Blocking of the ventilation zone during smoking could have the effect of increasing the yields of smoke components relative to those obtained from unblocked cigarettes. For more than twenty years studies have been undertaken to determine the incidence of vent blocking among smokers and it has been claimed that vent blocking is a significant aspect of human smoking behavior. For example, some studies have been interpreted to imply that more than $50 \%$ of smokers block the ventilation holes inadvertently with their fingers and lips, or even deliberately with tape (28). Other studies, however, report much lower incidences of vent blocking $(6,40)$.
The objectives of this review are twofold: to examine critically the evidence from smoking behavior studies of the incidence of filter vent blocking by smokers and to assess the effects of vent blocking as it might occur in practice on the yields of smoke components to the smoker.

We presented an earlier review of this subject at the Tobacco Chemists' Research Conference in WinstonSalem, NC, USA in 1997 and a printed copy of the presentation was given to all attendees at that meeting (5). Since that time several relevant studies have been published in the literature or presented at conferences. These give important insights into the subject. The present review is an update of the 1997 paper, with some of the earlier work summarized.

\section{SECTION 1. MEASUREMENTS OF INCIDENCE OF FILTER VENT BLOCKING}

Three methods of visually determining whether vent blocking has occurred have been used in studies over more than twenty years: determination from the pattern of 'tar' stains at the mouth end of the filter; direct videorecorded observation; and visual observation of lipstick stains or the equivalent visualization of saliva stains on the filter tipping. In addition, smokers have been interviewed to assess their opinions as to whether or not they thought they blocked the ventilation zone.

\subsection{Measurement by filter 'tar' stain technique}

Estimation of the occurrence of filter vent blocking from the pattern of 'tar' stains at the mouth end of the filter was first suggested by KOZLOwSKI et al. in 1980 (20). They claimed that a central staining or "bull's-eye" pattern, where the brown 'tar' stain occurs only in the center of the mouth end of the filter, indicated that no vent blocking had occurred. Air drawn in through the ventilation zone travels along the peripheral region of the filter and forces the smoke to the central region of the filter. Conversely, they reported that a heavy stain pattern across the entire filter end indicated that the vents had been completely blocked; a lighter stain across the filter corresponded to vents that had been partially blocked. Six studies have been published since 1982 using the technique and the results are summarized in Table 1. Brief details of these studies follow in chronological order of publication.

In the first study using the technique, KOZLOwsKi et al. in 1982 (21) examined the filter stain patterns on 39 filters obtained after 39 subjects had each smoked one cigarette during an interview. They concluded that $15 \%$ of the filters were "probably blocked very effectively", and 44\% were "partially blocked" but stated that "these were impossible to judge with any confidence". 
Table 1.

Reported vent blocking incidence using filter 'tar' stain technique

\begin{tabular}{|c|c|c|c|c|}
\hline Reference & $\begin{array}{l}\text { Number } \\
\text { of filters }\end{array}$ & $\begin{array}{l}\% \text { Completely } \\
\text { blocked (no.) }\end{array}$ & $\begin{array}{l}\% \text { Partially } \\
\text { blocked (no.) }\end{array}$ & Number of subjects \\
\hline KOZLOWSKI et al., 1982 (21) & 39 & $15(6)$ & $44(17)$ & 39 \\
\hline ZACNY and STITZER, 1988 (62) & 1631 & $0.1(2)$ & $28(457)^{a}$ & 10 \\
\hline KozLOWSKI et al., 1988 (22) & 135 & $19(25)$ & $39(53)$ & Not reported \\
\hline KOZLOWSKI et al., 1989 (23) & 14 & $21(3)$ & $29(4)$ & 14 \\
\hline KozLowSKI et al., 1994 (25) & 158 & $27(43)$ & $26(42)$ & Not reported \\
\hline DJORDJEVIC et al., 2000 (11) & $-^{b}$ & $-^{c}$ & $21^{\mathrm{c}}$ & $\begin{array}{l}56 \text { "low yield" cigarette } \\
\text { smokers }\end{array}$ \\
\hline DJORDJEVIC et al., 2000 (11) & $-^{\mathrm{b}}$ & $-^{c}$ & $30^{c}$ & $\begin{array}{l}77 \text { "medium yield" } \\
\text { cigarette smokers }\end{array}$ \\
\hline
\end{tabular}

${ }^{a}$ The $28 \%$ partially blocked filters were categorized as $6 \%$ partially blocked and $22 \%$ questionably blocked or not blocked. ${ }^{b}$ Not reported but estimated from the publication that about 60 filter butts were generated from each subject.

cEvidence of some blocking but proportion of completely and partially blocked filters not reported.

In 1988 ZACNY and STITZER (62) conducted a five-week study with ten subjects who normally smoked "highyield" cigarettes $(1.0 \mathrm{mg}$ smoke nicotine, as measured on a smoking machine under conditions specified by the US Federal Trade Commission (FTC), or the International Organization for Standardization (ISO), i.e., one $35 \mathrm{~mL}$ puff of $2 \mathrm{~s}$ duration taken once per minute). Four cigarette brands were used in the study, with similar draw resistances and FTC smoke nicotine yields of 0.1, 0.4, 0.7 and 1.1 (unventilated) $\mathrm{mg}$. Each subject smoked one of the brands, in random order, over four 5-day sessions. In each session, the subject smoked as many cigarettes as desired and collected the butts. When the collected filters were examined, ZACNY and STITZER found that

[f]ilters from the 0.4 and $0.7 \mathrm{mg}$ nicotine-yield cigarettes could not be analyzed using the four stain pattern categories because it was impossible to distinguish between unblocked and partially blocked vents.

Note: The four categories of stain patterns were unblocked, completely blocked, partially blocked and "questionable"/undecided.

Over 1600 returned butts from the 0.1 nicotine mg brand were classified by the mouth end filter stain pattern and the results are given in Table 1 . The $28 \%$ partially blocked filters were actually categorized as $6 \%$ definitely partially blocked and $22 \%$ questionably blocked or not blocked.

KOZLOWSKI and co-workers published three additional studies $(22,23,25)$ using the filter 'tar' stain technique between 1988 and 1994, and the results are also shown in Table 1. In the first of these studies, they collected approximately 1000 cigarette butts from public ashtrays in Toronto and selected 135 for vent blocking determination. These were ventilated filters from cigarettes with FTC 'tar' yields of $4 \mathrm{mg}$ or less (22). In the next study in Toronto in 1989, KOZLOWSKI et al. (23) estimated the incidence of vent blocking on 14 filters collected from 14 subjects who had smoked during an interview. In the third study in 1989, KOZLOWSKI et al. (25) measured vent blocking on 158 discarded cigarette butts collected from ashtrays on an American university campus. These butts were estimated to have been from cigarettes yielding 8-12 mg FTC 'tar'.

The most recent study using this technique was published by DJORDJEVIC et al. in 2000 (11). Cigarette butts were collected over four days from 56 smokers of "low yield" cigarettes $(\leq 0.8 \mathrm{mg}$ nicotine/cigarette [FTC machine smoking]) and 77 smokers of "medium yield" cigarettes (0.9-1.2 mg nicotine/cigarette). The subjects smoked their usual brand in the study, although not all of the "medium yield" brands had ventilated filters. The filters were collected from each smoker over four days but actual numbers of filters examined were not reported. Differences between totally and partially blocked vents were also not reported. Nevertheless, it is the largest study conducted using this technique.

The results from the first five studies in Table 1 were the basis of the claim reported to the US FTC in $1996(24,54)$ that about $50 \%$ of smokers block the vent zone. KOZLOWSKI and co-workers conducted four of the studies and the number of butts examined in each study was small, ranging from 14 to 158 . The fifth study by ZACNY and STITZER examined a much larger number of butts, 1631, but these were from 10 smokers only. This study shows a much smaller prevalence of vent blocking. The large study of DJORDJEVIC et al. represented 133 smokers with the butts collected from each smoker over four days. This study also showed a lower total percentage of blocked vents.

\subsection{Consideration of filter stain patterns}

The use of the 'tar' staining patterns to estimate the degree of vent blocking is a difficult technique to do properly. Its use requires technicians (called 'raters') to be 
trained to estimate the degree of hole blocking from the stain pattern using a subjective scoring system. LOMBARDO et al. (31) conducted a study in 1983 to determine how accurately the technicians (albeit 'untrained' technicians in their study) could discriminate the stain patterns with unblocked, partially blocked, and completely blocked ventilation holes. The filters were generated by smoking the cigarettes with various levels of hole blocking both by machine and by subjects smoking ad libitum. Overall, they found that $79 \%, 52 \%$, and $90 \%$ of unblocked, partially blocked, and completely blocked filters were correctly identified. They stated,

[i]t is possible that, even with trained raters, the detection of ventilation hole blocking in smokers may prove too unreliable to be useful.

More recent work by PILlitTeri, MORSE and KOZLOWSKI (39) and KOZLOWSKI et al. (27) have led them to conclude that the technique cannot validly discriminate between $50 \%$ and $100 \%$ vent blockage, and that it is best suited to detect the presence versus the absence of vent blocking.

In addition, the 'tar' stain pattern also depends on the physical characteristics of the cigarette as well as level of vent blocking. Studies by Helms $(17,18)$ have shown that even with completely unblocked ventilation zones, the filter stain pattern obtained depends on various factors such as the degree of ventilation, the number and size of the ventilation holes, the number of rows of holes, and the depth into which the holes perforate the filter. Depending on the combination of these factors, 'tar' stain patterns of unblocked ventilated filters can range from a distinct "bull's eye" pattern to a completely diffuse staining pattern across the filter end. It is also possible that the influence of the filter ventilation on the "bull's eye" pattern might be blurred by the use of high permeability cigarette paper.

This is further illustrated in the work of SHIBATA et al. (53), who measured the distribution of nicotine in smoke flowing along the cross-section of ventilated filter cigarettes as the smoke exits the mouth end of the cigarette. They used specially constructed cigarette holders consisting of concentric tubes to sample the smoke at different positions across the cross-section of the mouth end of the filter. The cigarettes were machine-smoked under standard conditions. The smoke exiting the filter was drawn into the concentric tubes of various diameters in a series of experiments. The nicotine in the smoke streams was measured by gas chromatography. In this way they determined the cross-sectional distribution of smoke nicotine at filter ventilation levels of 0,28 , and $69 \%$. Their results indicate that at a filter ventilation level of $69 \%$, the smoke nicotine is flowing predominantly in the central core of the filter, which would produce a pronounced "bull's eye" stain. Also, with no filter ventilation, the smoke nicotine is distributed much more evenly along the cross section of the filter, resulting in a diffuse staining pattern across the filter. The smoke nicotine distribution at $28 \%$ ventilation is intermediate between 0 and $69 \%$ ventilation and would result in a fairly diffuse staining pattern across the filter rather than a distinctive "bull's eye".

We therefore conclude that the presence or absence of a distinctive "bull's eye" staining pattern may not be related to the occurrence of vent blocking. The conclusions from studies that have used this technique are thus questionable.

\subsection{Data from interviews with smokers}

In 1996 KOZLOWSKI et al. (26) reported the results of a random-digit dialing phone survey among American smokers. The sample consisted of 218 ultra-low 'tar' smokers, 360 "light" 'tar' smokers, and 210 "regular" 'tar' smokers. In this survey, two-thirds of the smokers were unaware of the presence of the vents or the consequences of blocking them. Ten percent of respondents in the "ultra-low" and "light" categories and 18\% of "regular" smokers who said they knew about vents reported that they believed that they blocked them during smoking. The majority of these self-reported blockers ( $41 \%$ to $51 \%$ ) said that they believed they had used their fingers for blocking, while only $0 \%$ to $7 \%$ said they thought they had blocked the vents with their lips. In addition, $16 \%$ to $36 \%$ said that they had used tape to block the vent holes. It is interesting to note from this survey that more respondents who were aware of the vents stated that they learned about them from television advertisements $3 \%$ of each category) than those who reported blocking them at the current time (1\% to $2 \%$ ). (Cigarette advertisements on television were discontinued in the United States in early 1971, about the time filter ventilation was becoming a means to lower 'tar' yields.)

A more recent telephone survey by KOZLOwsKI $e t$ al. in 1998 (29) was conducted among ultra-light, light, and "regular" (full-flavor) brand smokers in Massachusetts and among "regular" smokers across the United States. Key questions were whether the smoker had seen or ever heard of a small ring of holes around the filters of some cigarettes and whether their own current brand had these holes. The researchers purchased a sample of the respondents' usual brands and rated the visibility of the ventilation zone $(0=$ clearly visible to $5=$ impossible to see) . About $40 \%$ of all smokers in both samples knew that some cigarettes are ventilated, and about $20 \%$ reported vents on their own brand. Smokers from brands with no vents were excluded from the analysis. About $3 \%$ of higher 'tar' smokers reported that their brand was ventilated, and the researchers rated many of those cigarettes as having "hard-to-see" vents (score greater than 4). About one-third of the smokers of cigarettes with "easy-to-see" vents (score less than 1) reported that they were aware of the vents. The authors concluded that smokers should be educated about the presence and function of filter vents. 
Table 2.

Responses to questions on smokers' perceptions, FERRIS, 1983 (15)

\begin{tabular}{|c|c|c|c|}
\hline \multicolumn{3}{|c|}{$\begin{array}{l}\text { Do you block the ventilation holes during } \\
\text { normal smoking? }\end{array}$} & $(N=97)$ \\
\hline Yes $=52 \%$ & \multicolumn{2}{|c|}{ Don't know $=21 \%$} & \\
\hline \multicolumn{3}{|c|}{ How would this blocking be brought about? } & $(N=41)$ \\
\hline \multirow{2}{*}{\multicolumn{2}{|c|}{$\begin{array}{l}\text { During normal holding of the cigarette } \\
\text { Don't know }\end{array}$}} & $7 \%$ & \\
\hline & & $29 \%$ & \\
\hline \multicolumn{3}{|c|}{$\begin{array}{l}\text { What proportion of the puffing time would the } \\
\text { holes be blocked? }\end{array}$} & $(N=40)$ \\
\hline Puffing time (\%) & \multicolumn{2}{|c|}{ Responses (\%) } & \\
\hline 0 & \multicolumn{2}{|l|}{0} & \\
\hline 25 & \multicolumn{2}{|l|}{15} & \\
\hline 50 & \multicolumn{2}{|l|}{42.5} & \\
\hline 75 & \multicolumn{2}{|l|}{20} & \\
\hline 100 & \multicolumn{2}{|l|}{10} & \\
\hline Don't know & \multicolumn{2}{|l|}{12.5} & \\
\hline
\end{tabular}

\subsection{Video-taped observations}

In 1983 FERRIS (15) conducted a study in which the smoking behaviors of 133 smokers were video-recorded during interviews conducted in three British cities (Bristol, Sheffield and Southampton). After the interviews, the videos were viewed to determine the incidence of finger blocking of the filter ventilation zone. The subjects were recruited from known smokers of filterventilated cigarettes by an independent market research organization. Two psychologists from University College, Cardiff, undertook the one-to-one interviews. However, the real smoking nature of the study was not disclosed to the subjects, as they had been asked to participate in a study devoted to how they coped with day-to-day problems. Smoking per se was not mentioned to the subjects. The subjects were told that the interviews would be video-recorded "in order to analyze the answers later". During the interview, the subjects generally spontaneously chose to smoke.

At the end of the interview and its smoking session, the interviewer asked the subjects some questions about cigarettes and filter ventilation holes. These questions were designed to be perceived as incidental questions asked by the interviewer for his own interest. The objective of this session was to clarify the relationship between observational data and systematic interview data. The questions included the subjects' own perceptions of blocking the holes while smoking, and what proportion of the time the subjects see themselves blocking the holes. The video part of the study was specifically looking at the incidence of finger contact with the cigarette.

Excluding the lighting puff, the subjects took an average

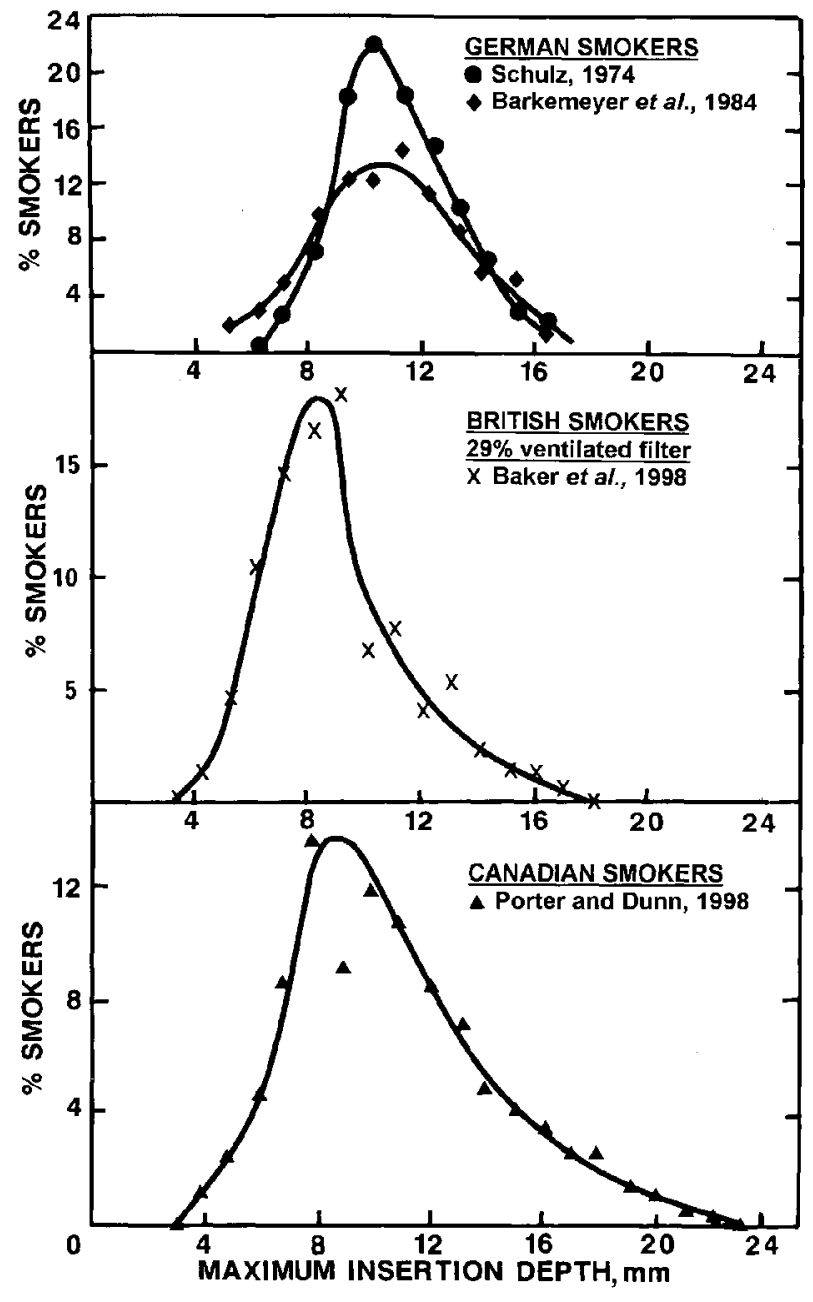

Figure 1.

Mouth insertion depth distributions

of 6 puffs each and a total of 798 puffs were assessed individually from the video recordings. The video recordings demonstrated clearly that the subjects generally released the cigarette when they took a puff. The results indicate that $87 \%$ of the puffs were taken with the fingers not in contact with the cigarette. Only 15 subjects $(11 \%)$ had their fingers in contact with the cigarette for one or more puffs. Of these, 5 subjects $(4 \%)$ had their fingers in contact with the cigarette during all puffs. It should be noted that "fingers in contact with the cigarette" does not mean that the fingers were in contact with the filter ventilation zone. An independent video-recording study of 23 smokers undertaken by HILL (19) indicated that finger contact, when it does occur during a puff, is 15 to $24 \mathrm{~mm}$ from the cigarette mouth end, mean of $18.3 \mathrm{~mm}$. The position of the vent zone is typically 11 to $16 \mathrm{~mm}$ from the cigarette mouth. Thus HILL's study demonstrates that most finger contact with the cigarette, when it does occur, is upstream of the filter ventilation zone.

The key results from FERRIS' post-observational 'incidental' questions are shown in Table 2. The post interview 
Table 3.

Summary of cigarette mouth insertion depth measurements

\begin{tabular}{|c|c|c|c|c|c|}
\hline \multirow[b]{2}{*}{ Study } & \multicolumn{2}{|c|}{$\begin{array}{l}\text { Maximum insertion } \\
\text { depth }(\mathrm{mm})\end{array}$} & \multirow[b]{2}{*}{$\begin{array}{l}\text { No. of } \\
\text { filter butts }\end{array}$} & \multirow[b]{2}{*}{ Method } & \multirow[b]{2}{*}{ Reference } \\
\hline & Mean & $\begin{array}{l}\text { Standard } \\
\text { deviation }\end{array}$ & & & \\
\hline $\begin{array}{l}\text { Germany, } 300 \text { smokers } \\
\text { (pubs, etc.) }\end{array}$ & 10.9 & 2.1 & 441 & Lipstick & SCHULZ, 1974 (51) \\
\hline $\begin{array}{l}\text { Germany, } 41 \text { smokers } \\
\text { (pubs, etc.) }\end{array}$ & 11.5 & 3.0 & 560 & Amylase & BARKEMEYER et al., 1984 (7) \\
\hline $\begin{array}{l}\text { Switzerland } \\
\text { (pubs, etc.) }\end{array}$ & 10.4 & 3.8 & 1410 & Amylase & BARKEMEYER et al., 1984 (7) \\
\hline $\begin{array}{l}\text { Canada, non-ventilated } \\
\text { cigarettes (shopping malls) }\end{array}$ & 11.0 & 4.6 & 290 & Amylase & MCBRIDE, 1984 (35) \\
\hline $\begin{array}{l}\text { Canada, ventilated cigarettes } \\
\text { (shopping malls) }\end{array}$ & 11.1 & 4.8 & 205 & Amylase & MCBRIDE, 1984 (35) \\
\hline $\begin{array}{l}\text { Canada, non-ventilated } \\
\text { cigarettes (shopping malls) }\end{array}$ & 11.0 & 3.6 & 1003 & Ninhydrin & PORTER and DUNN, 1998 (40) \\
\hline $\begin{array}{l}\text { Canada, ventilated cigarettes } \\
\text { (shopping malls) }\end{array}$ & 10.6 & 3.6 & 1229 & Ninhydrin & PORTER and DUNN, 1998 (40) \\
\hline $\begin{array}{l}\text { USA (in-house and public } \\
\text { ashtrays) }\end{array}$ & 10.1 & 3.9 & 236 & Ninhydrin & LEWIS, 1995 (30) \\
\hline $\begin{array}{l}\text { UK, non-ventilated } 12 \text { mg 'tar' } \\
\text { cigarette (home study) }\end{array}$ & 7.8 & 3.6 & 1802 & Ninhydrin & BAKER et al. 1998 \\
\hline $\begin{array}{l}\text { UK, ventilated } 9 \text { mg 'tar' } \\
\text { cigarette (home study) }\end{array}$ & 8.7 & 3.7 & 1821 & Ninhydrin & BAKER et al. 1998 (6) \\
\hline $\begin{array}{l}\text { UK, ventilated } 4 \text { mg 'tar' } \\
\text { cigarette (home study) }\end{array}$ & 9.5 & 5.0 & 1852 & Ninhydrin & BAKER et al., 1998 (6) \\
\hline \multirow[t]{2}{*}{ UK (laboratory study) } & Max. 8.3 & 2.6 & 26 & Amylase & HILL, 1983 (19) \\
\hline & Min. 5.3 & 3.0 & & & \\
\hline
\end{tabular}

answers came from a subset of those asked and deal with the subjects' own perceptions of their smoking behavior. The interview findings are similar to those of KOZLOWSKI et al. $(20,23,26)$ and indicate a perceived high level of blocking. However, from the observed video behavior of the same subjects, it is clear that vent blocking by fingers is fairly minor. What subjects do and what they think they do in smoking behavior may be quite different. The use of smokers' own perceptions is thus unlikely to give valid information about filter vent blocking behavior.

\subsection{Mouth insertion depth studies}

Several studies conducted independently have measured the depth to which smokers insert cigarettes into their mouths and the techniques used have evolved since the 1970s. The early studies were unpublished but their findings were summarized in 1997 (5). Two comprehensive studies have been published since that review was written $(6,40)$. Most of the studies have involved examining used filter cigarette butts from ashtrays in pubs, restaurants, shopping areas, and other public areas and obtaining a visible imprint of the lip marks on the tipping. The earliest study in Germany in 1974 (51) used lipstick stains on the filter as the basis of the measurement and was, presumably, limited to women smokers. (KOZLOWSKI et al. (21) have also reported the use of lipstick stains as an indicator of vent blocking but did not use them to measure mouth insertion depths.) Studies conducted in Germany and Switzerland (7) and Canada (35) used the detection of the enzyme $\alpha$-amylase in dried saliva on the butts. The method is dependent on the breakdown of starch to oligosaccharides which are catalyzed by $\alpha$-amylase. Visualization of the lip imprint involves the use of starch and iodine solutions. The reaction is extremely sensitive and the $\alpha$-amylase in dried saliva on cigarette butts is detectable even after several weeks (7). Preliminary experiments using the $\alpha$-amylase method showed good correlations between the measured insertion depths and direct video-recording observation $(19,59)$.

Although very sensitive for the detection of saliva, the $\alpha$ amylase technique involves a number of steps and is time consuming. More recent studies conducted in the USA, UK and Canada have been based on the detection of amino acids in the dried saliva on the filter using aqueous solutions of ninhydrin $(6,30,40)$. The ninhydrin technique is not a perfect technique and there are uncertainties in its use. For example, amino acids are present in all 


\section{No coverage}

$v \geq d_{\mathrm{i}}$
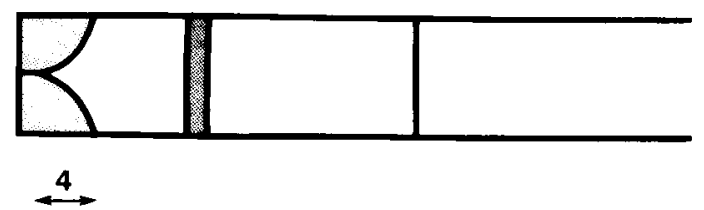

Partial coverage

$d_{\mathrm{i}}>v>\left(d_{\mathrm{i}}-4-x\right)$ or

$v<d_{\mathrm{i}}<(v+4+x)$

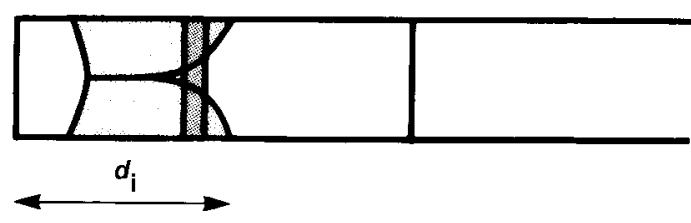

Complete coverage

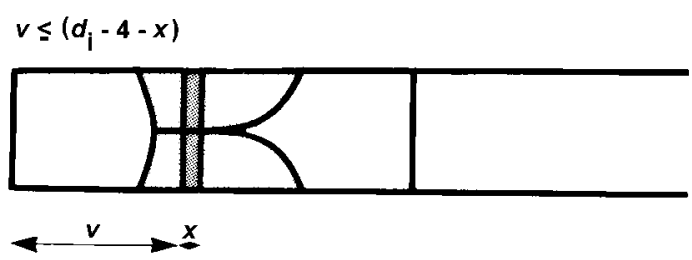

Figure 2.

Ventilation zone coverage by lips

body fluids, including perspiration on fingers. Occasionally finger marks were observed on the ninhydrin-stained filter papers in addition to the lip imprint. However, it was generally easy to distinguish the stained lip imprint from the stained finger marks. Furthermore, results from the UK study (6) show that following the staining treatment, about $11 \%$ of the filter tipping papers examined had no distinct lip imprint. This is presumably due to the smokers of these cigarettes having dry lips, which did not leave any saliva on the filter. These cigarettes were smoked in the UK in May and June 1997, a relatively humid period. In the Canadian study (40), the butts were collected from indoor shopping malls during the winter of 1996/97 and 19\% of the filter tipping papers had no distinct lip imprint. The humidity in these environments in the winter would be much lower than in the UK in May/June, resulting in a higher proportion of smokers with dry lips.

HILL (19) also used a different experimental approach when he video-recorded smokers, in profile, in a laboratory-based study. The cigarette mouth insertion depths were then measured from the video recordings.

Typical distributions of observed mouth insertion depths from four studies are shown in Figure 1 and a summary of the various studies is given in Table 3. Insertions depths range from 3 to $25 \mathrm{~mm}$, and mean mouth inser- tion depths varying from 10.1 to $11.5 \mathrm{~mm}$ have been observed in the studies conducted in Germany, Switzerland, Canada and the USA between 1974 and 1998. These studies indicate that the observed insertion depths have remained relatively constant over a twenty-year period and across four countries.

The mean mouth insertion depths for UK smokers $(6,19)$ are shorter than those reported for other nationalities using similar staining techniques and direct observation by video recording. Mean insertion depths for UK smokers ranged from 7.8 to $9.5 \mathrm{~mm}$. In the more recent study there was also a significant dependence of insertion depth on cigarette 'tar' (i.e. degree of filter ventilation), with insertion depths being in the order: $4 \mathrm{mg}$ cigarette $>9 \mathrm{mg}>12 \mathrm{mg}$. This is in agreement with preliminary indications from the 1984 studies on Swiss and Canadian smokers $(7,35)$ but is in contrast to the comprehensive 1998 Canadian study (40). Further aspects of the 1997 UK study (6) are discussed in Section 4 of this review.

Apart from the values reported by HiLl (19), all of the insertion depths included in Figure 1 and Table 3 are maximum values, i.e., the maximum distance from the mouth end of the cigarette to the outer limit of the region covered by the lip imprint. There is no way of estimating whether this maximum insertion depth was achieved in every puff using results from the staining techniques - it could have been achieved in one puff only, before the cigarette was lit, or between puffs. Consideration of these insertion depth measurements can be used to analyze the coverage of the filter ventilation zone by lips during smoking. For a given ventilation zone position in a given puff, there are three conditions to consider, illustrated in Figure 2.

i. Distance from the cigarette mouth end to the edge of the ventilation zone $(v)$ is greater than the maximum measured insertion depth $\left(d_{\mathrm{i}}\right), v \geq d_{\mathrm{i} \text {. Clearly the }}$ ventilation zone is not covered by the lips.

ii. Ventilation zone is between measured maximum $\left(d_{\mathrm{i}}\right)$ and minimum $\left(d_{\min }\right)$ insertion depth - the ventilation zone will be partially covered by the lips, i.e., $d_{\mathrm{i}}>v$ and $d_{\min }<(v+x)$, where $x$ is the width of the ventilation zone.

Careful observation of the lip imprints on the filters $(7,19)$ and video recordings of smokers $(19,59)$ has shown that the average distance between maximum and minimum insertion $\left(d_{\mathrm{i}}\right.$ and $\left.d_{\text {min }}\right)$ with a given smoker varies between 3 and $5 \mathrm{~mm}$ in a given puff. Thus we can set the average $d_{\min }$ as $\left(d_{\mathrm{i}}-4\right) \mathrm{mm}$. Thus the condition for partial coverage becomes:

$d_{\mathrm{i}}>v>\left(d_{\mathrm{i}}-4-x\right)$ or

$v<d_{\mathrm{i}}<(v+4+x)$.

iii. Distance from the cigarette mouth end to the far edge of the ventilation zone $(v+x)$ is less than minimum insertion depth $\left(d_{\min }\right)$ - ventilation zone will be completely covered by the lips:

$(v+x) \leq d_{\text {min }}$

i.e., $v \leq\left(d_{\mathrm{i}}-4-x\right)$. 


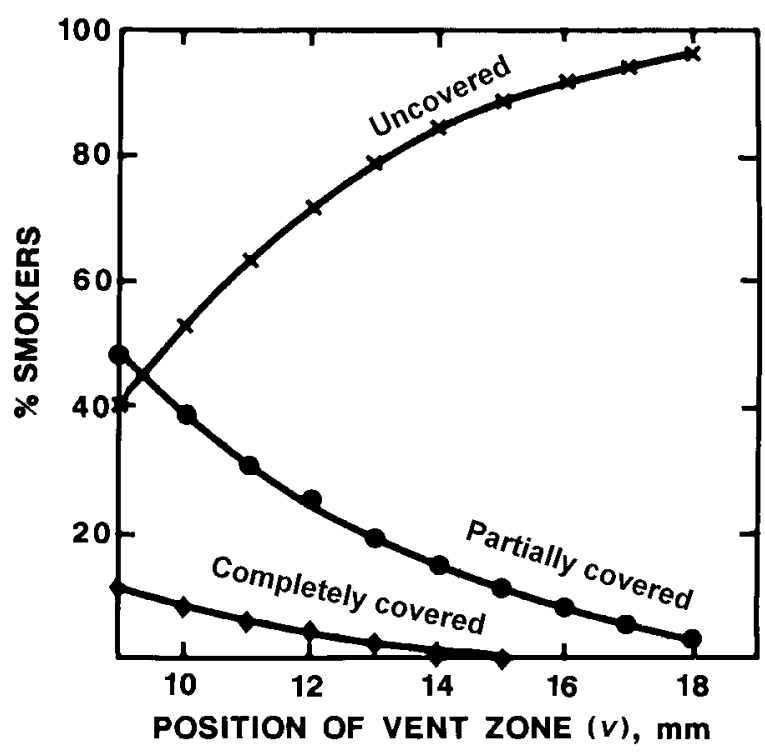

Figure 3.

Calculated effect of position of ventilation zone on hole coverage by smokers

Using these conditions and the observed insertion depth distributions (Figure 1), the proportion of smokers that would achieve completely uncovered, partially covered, and completely covered holes as a function of the ventilation zone position can be calculated. Some typical calculated results are shown in Figure 3, based on a ventilation zone width of $2 \mathrm{~mm}$ and the Canadian insertion depth distribution of 2232 butts (40). This latter distribution is one of the most comprehensive available and only relatively minor differences are obtained if the other distributions depicted in Figure 1 are used.

The proportion of smokers who block vents is obviously dependent on the position of the vent zone; the further it is up the filter, the smaller the proportion of smokers that can potentially block it (Figure 3). Leading ventilated brands typically have a ventilation zone starting at between 11 and $16 \mathrm{~mm}$ from the mouth end. At $11 \mathrm{~mm}$, $36 \%$ of smokers could cover the vent zone, the majority of whom (84\%) would do so partially. At $16 \mathrm{~mm}, 8 \%$ of smokers could cover the vent zone and virtually all of them $(98 \%)$ would do so partially. For the two largest and most recently published studies $(6,40)$, the cigarettes were smoked during normal day-to-day situations and exact information on the ventilation zone positions on the cigarette filters was also available. Thus exact information on the proportion of the vents blocked during at least one puff while the cigarette was smoked can be obtained. This information is summarized in Table 4.

RÖPER (45) has used image analysis of lip imprints from one puff to give further information on the proportion of smokers who block the ventilation zone. In this study the subjects applied lip cream to their lips and took one puff on a ventilated filter cigarette. The cream enabled a very sharp image to be obtained following spraying of the filter with iodine solution. In total, 52 subjects from the
Table 4.

Extent of ventilation hole coverage among smokers from mouth insertion depth studies, BAKER et al., 1998 (6), PORTER and DUNN, 1998 (40)

\begin{tabular}{lrc}
\hline Study & UK & Canada \\
\hline No vent coverage & $85 \%$ & $76 \%$ \\
Partial coverage & $11 \%$ & $19 \%$ \\
Complete coverage & $4 \%$ & $5 \%$ \\
Number of filters examined & 3673 & 1229 \\
\hline
\end{tabular}

staff of Reemtsma GmbH, a tobacco company in Hamburg, Germany, smoked 5 cigarettes of each of three filter-ventilated brands. The start of the ventilation zones were positioned $11 \mathrm{~mm}$ from the mouth end of the cigarette. Sharp lip imprints were obtained from 735 smokings. Some coverage of the ventilation zone by the lips was observed with 354 of the imprints, although it was less than $10 \%$ for 111 of the imprints. The $48 \%$ lip contact with a vent zone positioned $11 \mathrm{~mm}$ from the mouth end is higher than the $36 \%$ from Figure 3 at 11 $\mathrm{mm}$. This difference may have been caused by the somewhat unnatural smoking situation in RÖPER's laboratory-based study or from the cream on the lips causing "sliding" of the filter tip. RÖPER's image analysis showed that the ventilation zone coverage was partial for all cases showing some coverage, with an overall mean of $27 \%$ of the ventilation zone area covered, standard deviation $24 \%$. For over $80 \%$ of those smokers who did have lip contact with the vent zone, the maximum coverage of the ventilation zone area was $50 \%$.

\section{SECTION 2.}

\section{EFFECTS OF VENT BLOCKING ON CIGARETTE VENTILATION AND MACHINE SMOKE YIELDS}

The literature indicates that there is a non-linear relationship between air flow through perforated paper and the pressure drop across the paper $(2,4,12,33,34,38,42,52)$, caused by inertial forces as the air flows through the perforation holes. SCHNEIDER et al. (49) showed that the relationship between filter ventilation of a cigarette and effective air permeability of the filter ventilation zone is non-linear. The air permeability of the ventilation zone is proportional to the number of holes in the zone $(4,38)$. Thus it may be deduced that the relationship between the degree of blocking of the filter ventilation zone and filter ventilation is also non-linear. This has been confirmed in several studies $(6,10,19,44-46)$. The non-linearity increases as the filter ventilation increases.

The non-linear ventilation/degree of blocking relationships are also reflected in the non-linear relationships 

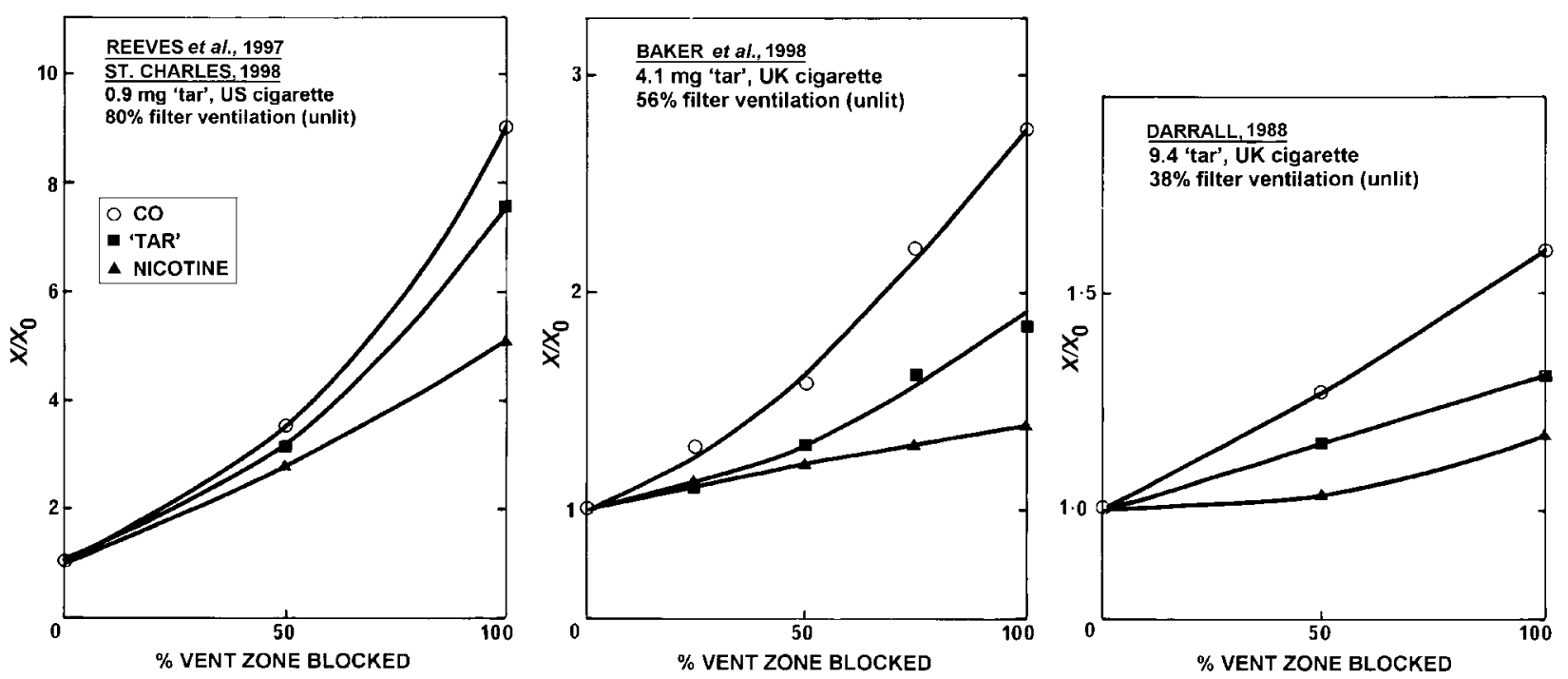

Figure 4.

Effect of vent blocking on yield of smoke components $(X)$ relative to unblocked yield $\left(X_{0}\right)$ - machine smoking (ISO) conditions
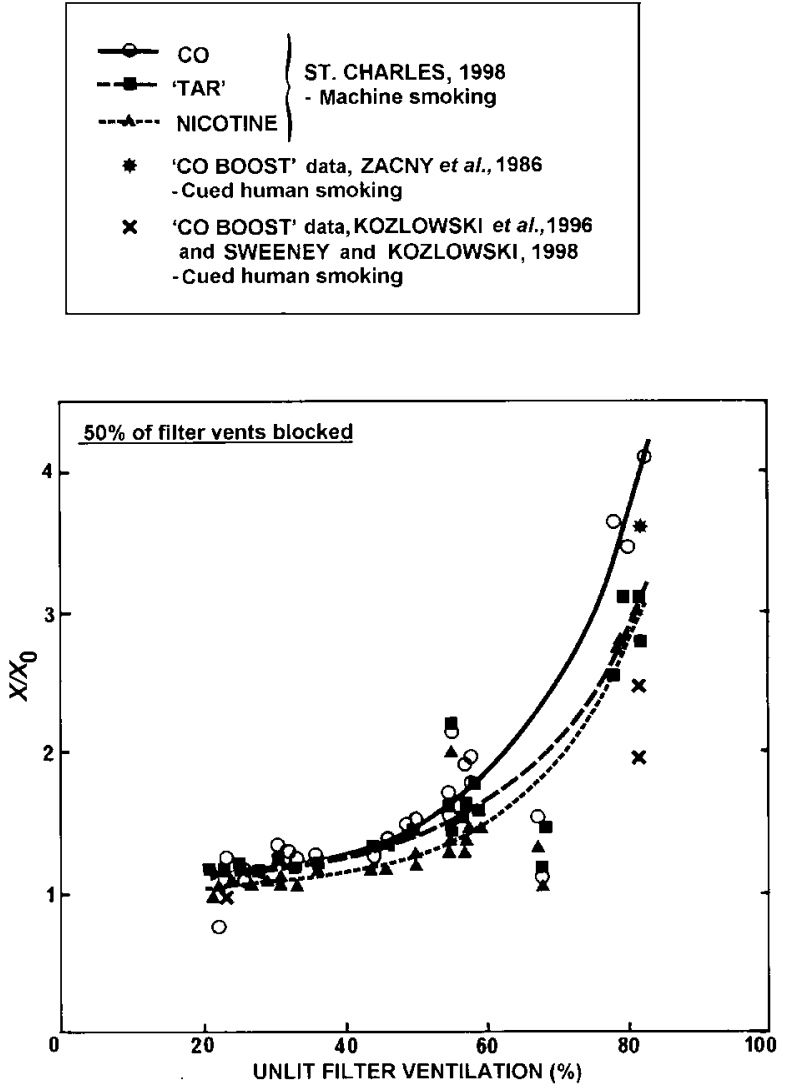

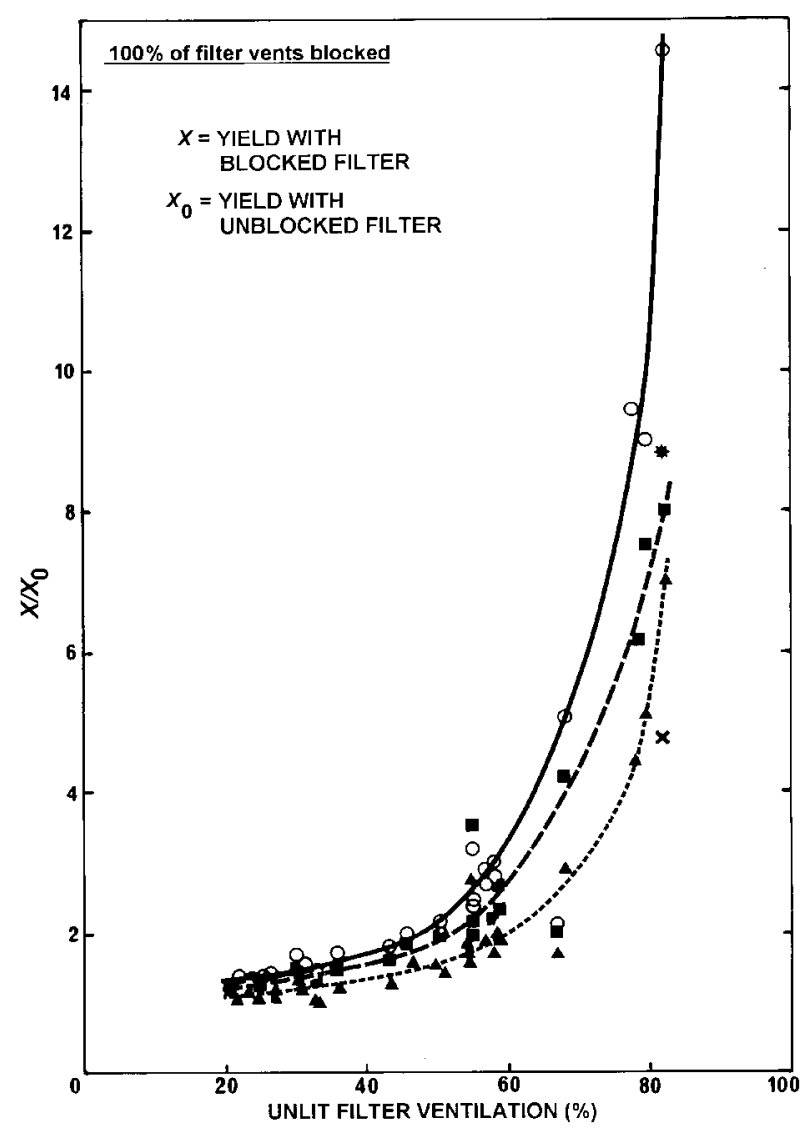

Figure 5.

Effect of magnitude of filter ventilation on relative increase in yield when filter vent zone is blocked - machine or constant (cued) human smoking regimen

between observed mainstream smoke yields under machine smoking conditions and percentage of filter vent holes blocked $(6,10,15,20,45-47)$. Four of these studies have reported data for 'tar', nicotine and carbon monoxide yields $(6,10,20,46)$. A large study by RICKERT et al. (43) also reported data for 'tar', nicotine and CO for 36 
Table 5.

Effect of deliberately blocking filter ventilation zone on "CO boost" - subjects cued to smoke at a fixed puffing regimen

\begin{tabular}{|c|c|c|c|c|c|}
\hline Reference & $\begin{array}{l}\text { FTC 'tar' } \\
\text { category of } \\
\text { cig. (mg) }\end{array}$ & $\begin{array}{l}\text { Vent zone } \\
\text { condition }\end{array}$ & $\begin{array}{l}\text { Mean "CO } \\
\text { boost" (SE) } \\
(\mathrm{ppm})\end{array}$ & Cued smoking regimen & $\begin{array}{l}\text { No. } \\
\text { of subjects }\end{array}$ \\
\hline $\begin{array}{l}\text { ZACNY et al., } \\
1986(61)\end{array}$ & 1 & $\begin{array}{l}\text { Unblocked } \\
50 \% \text { blocked }^{b} \\
100 \% \text { blocked }^{b}\end{array}$ & $\begin{array}{l}0.8 \\
2.9 \\
7.1\end{array}$ & $\begin{array}{l}\text { Eight } 60 \mathrm{~mL} \text { puffs every } 50 \mathrm{~s} \text {; } \\
\text { inhalation volume was } 50 \% \text { of vital } \\
\text { capacity; breathhold was } 3.5 \mathrm{~s}\end{array}$ & 5 \\
\hline $\begin{array}{l}\text { KoZLOWSKI et al., } \\
1996 \text { (27) }\end{array}$ & 1 & $\begin{array}{l}\text { Unblocked } \\
\text { Lip blocked } \\
100 \% \text { blocked }^{b}\end{array}$ & $\begin{array}{r}2.7(0.5) \\
6.7(1.0) \\
12.9(2.2)\end{array}$ & $2 \mathrm{~s}$ puff every $50 \mathrm{~s}$ & 12 \\
\hline \multirow[t]{3}{*}{$\begin{array}{l}\text { SWEENEY and } \\
\text { KOZLOWSKI, } \\
1998(55)\end{array}$} & 10 & $\begin{array}{l}\text { Unblocked } \\
50 \% \text { blocked }^{\mathrm{b}} \\
\text { Lip blocked } \\
\text { Finger blocked }\end{array}$ & $\begin{array}{l}5.0(0.5) \\
4.8(0.5) \\
4.9(0.9) \\
4.9(0.5)\end{array}$ & $2 \mathrm{~s}$ puff every $50 \mathrm{~s}$ & 12 \\
\hline & 1 & $\begin{array}{l}\text { Unblocked } \\
\text { Finger blocked }\end{array}$ & $\begin{array}{l}2.8(0.3) \\
5.4(0.6)\end{array}$ & $2 \mathrm{~s}$ puff every $50 \mathrm{~s}$ & 12 \\
\hline & 10 & $\begin{array}{l}\text { Unblocked } \\
\text { Finger blocked }\end{array}$ & $\begin{array}{l}6.3(0.5) \\
6.5(0.5)\end{array}$ & $2 \mathrm{~s}$ puff every $50 \mathrm{~s}$ & 12 \\
\hline
\end{tabular}

${ }^{\mathrm{a}} \mathrm{SE}=$ Standard error.

${ }^{b}$ Ventilation zone blocked with tape.

Canadian brands but at one vent block condition only (50\%). Some typical results from three studies are illustrated in Figure 4. These results were obtained when various 'tar' category cigarettes were machine-smoked, taking a $35 \mathrm{~mL}$ puff of $2 \mathrm{~s}$ duration once per minute after the ventilation zone had been systematically blocked using adhesive tape. The independent studies show very consistent trends. Four general observations can be made and rationalized from all of the smoking machine data taken as a whole:

1. The yield of a given smoke component increases in a non-linear manner as the percentage of blocked vent holes increases (Figure 4). It should be noted that the ordinate $\left(X / X_{0}\right)$ axes for data from the three cigarettes in Figure 4 are on different scales. Thus, the effect of vent blocking on machine yields for the 4.1 $\mathrm{mg}$ 'tar' cigarette is relatively small, and it is very small for the $9.4 \mathrm{mg}$ 'tar' cigarette.

2. For a given smoke component and degree of vent blocking, the magnitude of the increased machine yield relative to the unblocked condition increases in a non-linear manner as the filter ventilation (measured at an air flow of $17.5 \mathrm{~mL} \mathrm{~s}^{-1}$ ) of the cigarette increases, i.e. as the 'tar' yield decreases. This relationship is seen from the comprehensive data of ST. CHARLES (46) in Figure 5 for both 50\% and 100\% blocked vents.

3. The relative machine $\mathrm{CO}$ yields increase greatly at filter ventilation levels above about $80 \%$ when all the vents are blocked. This is due to the effect of filter ventilation on the diffusion processes of $\mathrm{CO}$ as the smoke is drawn through the cigarette (3).

4. For a given cigarette, the effect of a given degree of vent blocking on smoking machine yields is in the order of $\mathrm{CO}>$ 'tar' $>$ nicotine (Figures 4 and 5). This order is consistent with the findings of a review of several studies on the relative reductions of these smoke components by the introduction of filter ventilation, and is caused by the relative effects that the various combustion and physical processes occurring in a burning cigarette have on the generation and mass transfer of $\mathrm{CO}$, 'tar' and nicotine (3).

Concerning observation 2 above, ZACNY et al. (61), KOZLOWSKI et al. (27), and SWEENEY and KOZLOWSKI (55) have made measurements of "CO boost" (described in more detail in Section 3.1 below) with humans who smoked cigarettes by a cued pattern (with volume, interval, puff number, and duration controlled to some degree). Their data, discussed in more detail in Section 3.1 of this review, are also given in Figure 5 and are in reasonable agreement with the data of ST. CHARLES (46). SCHNEIDER (50) has shown that the general non-linear relationship for 'tar' in Figure 5 can be predicted exactly using a computer model of the physical processes occurring during smoke formation in a filter-ventilated cigarette. The relationship is thus a consequence of the interaction of the physical processes occurring during smoke formation. 
SECTION 3.

EFFECT OF EXPERIMENTALLY BLOCKING FILTER VENTS ON HUMAN SMOKE YIELDS

\subsection{Studies where subjects are cued to smoke the blocked cigarette to a given puffing regimen}

Three independent studies have been undertaken in which the ventilation zone was deliberately blocked by the experimenter $(27,55,61)$. They all measured the "CO boost" of subjects smoking vent-blocked cigarettes at specified and controlled smoking regimens. "CO boost" is described as the increase in carbon monoxide in the exhaled air of the smoker immediately after taking one puff, or immediately after smoking the cigarette, compared to immediately before smoking. It may be approximately related to the carbon monoxide yield in smoke. Five regular smokers of medium to high 'tar' yield brands (average FTC 'tar' $15.7 \mathrm{mg}$ ) took part in the study of ZACNY et al. (61). The subjects smoked $1 \mathrm{mg}$ 'tar' cigarettes (FTC method) with $0 \%, 50 \%$ and $100 \%$ of the ventilation holes deliberately covered, in a randomized order. Each subject was instructed to take one puff each from 8 freshly lit cigarettes. Puff volume $(60 \mathrm{~mL})$, puff interval ( $50 \mathrm{~s})$, inhalation volume ( $50 \%$ of vital capacity), and breathhold (3.5 s) were controlled (cued) during the smoking session. The observed mean "CO boosts" increased with degree of vent blocking (Table 5). The subjects were also asked to assess their sensory perceptions of the cigarettes and rated the completely blocked cigarettes as stronger, hotter and harsher than the partially blocked and unblocked cigarettes.

In these studies, the subjects were not allowed to smoke the blocked cigarettes freely but were cued to smoke to a set puffing regimen, rather like a smoking machine. It should also be noted that in the ZACNY et al. study (61), the subjects were regular smokers of relatively high 'tar' cigarette brands $(15.7 \mathrm{mg}$ on average under FTC conditions) who were required to smoke $1 \mathrm{mg}$ 'tar' cigarettes in the study.

"CO boost" measurements have also been used by KozLOwsKI et al. (27) to give an estimate of the maximum proportion of the ventilation zone that can be covered by a smoker's lips in practice. Twelve regular smokers took part in the study. Cigarettes of $1 \mathrm{mg}$ 'tar' yield (FTC method) were used in the experiments under three conditions: vents unblocked, vents completely blocked with tape, and a condition in which the subjects were instructed to insert the cigarette into their mouth as far as necessary in order to cover all the vents with their lips while smoking. For each vent-blocked condition, a pre-recorded tone was used so that the subjects took a $2 \mathrm{~s}$ puff every $50 \mathrm{~s}$. The mean "CO boosts" observed are shown in Table 5. From these data KozLOwsKI et al. (27) concluded that the lips had blocked about $50 \%$ of the vents. Given that the subjects had been specifically instructed to block the ventilation zone with their lips as much as possible, the mean figure of $50 \%$ is likely to represent the maximum area of the vent zone that can be covered by the lips in practice. It is the same as the maximum vent zone coverage estimated from RÖPER's image analysis for the majority of smokers in RÖPER's study (45), discussed in Section 1.5 above.

SWEENEY and KOZLOWSKI (55) have also conducted a similar study in which the subjects were asked to smoke $10 \mathrm{mg}$ 'tar' yield cigarettes (FTC method) under various conditions of deliberate ventilation zone blocking. The detailed results are also given in Table 5. In this study, the "lip blocked" condition is identical to that described above. For the "finger blocked" condition, subjects were instructed to hold the cigarette between their thumb and forefinger when taking a puff and thereby cover as many of the vents as possible. SWEENEY and KOZLOWSKI (55) estimate that this maneuver would block about $50 \%$ of the ventilation zone, similar to the estimation for lip blockage. The summarized results in Table 5 indicate that with a $10 \mathrm{mg}$ 'tar' cigarette smoked by humans to the cued puffing regimen, deliberate blocking of the ventilation zone has no effect on the "CO boost". This is clearly in contrast to the situation with $1 \mathrm{mg}$ 'tar' cigarettes when deliberate vent blocking produced a larger " $\mathrm{CO}$ boost" $(27,61)$. All the observations shown in Table 5 are consistent, however, with the machine-smoked results discussed in Section 2 above and illustrated in Figure 5. Under machine-smoking conditions and controlled human smoking in a manner analogous to smoking machines, the yield of a given smoke component varies in a non-linear manner with percentage of vent blockage, and the magnitude of the effect is dependent on the degree of filter ventilation and most likely the ' $t a r$ ' category of the cigarette.

SWEENEY and KOZLOWSKI (55) also reported that the subjects consistently rated the blocked $1 \mathrm{mg}$ 'tar' cigarettes as stronger, harsher and hotter than the unblocked cigarettes. For the $10 \mathrm{mg}$ 'tar' cigarettes, the subjects' subjective assessments were less consistent, varying from no effect of blocking in one comparison to stronger and harsher when blocked in another comparison.

The use of the "CO boost" measurement is problematic, however. Variable absorption of $\mathrm{CO}$ by smokers will introduce uncertainties, as will variability in the exhaled CO measure itself. WOODMAN et al. (60) have shown that the $\mathrm{CO}$ concentration in exhaled air following deep inhalation and $20 \mathrm{~s}$ breath-hold falls very rapidly for five minutes after smoking. They recommend that measurements of $\mathrm{CO}$ in exhaled air should not be made until five minutes after smoking. The studies by ZACNY et al. (61) and SWEENEY and KOZLOWSKI (55), discussed above, took the first of their replicate exhaled air samples, following deep inhalation and 15 or 20 s breath-hold, two minutes after the last puff was taken. Furthermore, GUYATT et al. (16) also postulate that the act of smoking itself induces a transient change in pulmonary gas exchange which invalidates measurements of the "CO boost" by the use of exhaled air. 
Table 6.

Effect of deliberately blocking filter ventilation zone on "CO boost" with ad libitum smoking, SWEENEY et al., 1999 (56)

\begin{tabular}{|c|c|c|c|}
\hline \multirow{2}{*}{$\begin{array}{l}\text { FTC 'tar' } \\
\text { category of } \\
\text { cig. (mg) }\end{array}$} & \multirow{2}{*}{$\begin{array}{c}\text { Filter } \\
\text { ventilation } \\
(\%)^{c}\end{array}$} & \multicolumn{2}{|c|}{$\begin{array}{c}\text { Mean "CO boost" (SE) } \\
(\mathrm{ppm})\end{array}$} \\
\hline & & Unblocked & Blocked \\
\hline \multicolumn{4}{|l|}{ Study $1^{a}$} \\
\hline 1 & $-^{d}$ & $2.0(0.6)$ & $3.7(0.5)$ \\
\hline 10 & 22.5 & $6.1(0.8)$ & $5.9(0.8)$ \\
\hline \multicolumn{4}{|l|}{ Study $2^{b}$} \\
\hline 1 & 82.5 & $1.8(0.4)$ & $6.1(0.9)$ \\
\hline 2 & 66 & $3.9(0.7)$ & $5.6(0.7)$ \\
\hline 5 & 56 & $5.0(0.9)$ & $5.8(0.7)$ \\
\hline 8 & 40 & $5.5(0.8)$ & $5.9(1.0)$ \\
\hline
\end{tabular}

${ }^{\text {aT }}$ Twelve smokers ( 6 men, 6 women) aged 19-33 years. Their regular brands were "full flavor" or "lights" cigarettes. Subjects were instructed to block as much of the vent zone as possible with their fingers.

${ }^{b}$ Twelve female smokers aged $18-50$ years. Their regular brands were all "lights" cigarettes. Subjects were instructed to block as much of the vent zone as possible with their lips.

'Measured at an air flow of $17.5 \mathrm{~mL} \mathrm{~s}^{-1}$.

${ }^{d}$ Not measured.

eStandard error.

\subsection{Studies in which the subjects smoked ad libitum}

In the most recent paper by SWEENEY et al. (56), subjects smoked various cigarette brands (FTC 'tar' yields between 1 and $10 \mathrm{mg}$ ) ad libitum in two series of experiments. The subjects were instructed to block as much of the marked ventilation zone as possible with their thumb and forefinger in the first series. In the second series, another group of smokers was instructed to block as much of the ventilation zone as possible with their lips. Both the lip and finger blocking maneuvers are believed to block a maximum of $50 \%$ of the vents $(27,55)$. In both series of experiments the subjects were then instructed to smoke the cigarette as they wished, i.e., puffing parameters were free to vary. The "CO boost" was measured after smoking each cigarette. A summary of their results is given in Table 6. Clearly, the effect of blocking the ventilation zone on "CO boost" fell as the 'tar' category of the cigarette increased and was not significant at 'tar' yields of $5 \mathrm{mg}$ or greater.

In 1997 REEVES and co-workers measured the effects of experimentally blocking the filter ventilation zone in a range of cigarettes on human smoking behavior and nicotine and 'tar' available to the smoker. REEVES, AYYA and ST. CHARLES have presented the detailed results in a series of papers at three conferences $(1,41,47)$.

In this study, three groups of consumers were recruited according to the FTC 'tar' yields of their regular brand of filter ventilated cigarette: $1-3 \mathrm{mg}$ (average filter ventila- tion, $\mathrm{FV}, 75 \%$ ), 4-6 $\mathrm{mg}$ (average FV 56\%) and 7-12 $\mathrm{mg}$ (average FV 30\%). Subjects visited a market research agency in Atlanta, GA, USA for monitoring of their smoking behavior. During this session the subjects were asked to smoke their own regular cigarette brand with ventilation holes intact, $50 \%$ blocked with adhesive tape, and $100 \%$ blocked. Two puffing behavior monitorings were conducted during smoking for each of the three conditions. The order of cigarette presentation under the three conditions was randomized across subjects and a specially designed plastic sleeve was positioned over the filter ventilation zone to prevent the subjects from seeing the adhesive tape.

Each subject smoked the cigarette through a holder connected to two pressure transducers as described by CREIGHTON et al. (9). The signals from the pressure transducers were stored in a microcomputer and calibration of the system allowed pressure and flows to be monitored during each puff. The butts from the cigarettes smoked during the monitoring sessions were collected and subsequently analyzed for the 'tar' and nicotine retained on the filter.

The subjects were also asked to collect the butts from their regular cigarette brand smoked normally in two locations: at home when the subjects opened a new pack of cigarettes and collected at least ten butts, and at the market research facility with the cigarettes unattached to the monitoring equipment (laboratory "free" smoking conditions). Half of the subjects participated in the puffing behavior portion of the study after completing the laboratory "free" and home smoking parts of the study over two consecutive days. The other half of the subjects undertook the puffing behavior portion of the study prior to the home and laboratory "free" parts.

A total of 26 brands and 48 subjects were studied: 5 brands/9 subjects for the 1-3 mg 'tar' category, 11 brands $/ 20$ subjects for the $4-6 \mathrm{mg}$ category and 10 brands/19 subjects for the 7-12 mg category. Results from the puffing behavior experiments showed a significant and systematic decrease in mean puff volume $(95 \%$ significance) and cumulative puff volume ( $99 \%$ significance) for the 1-3 mg and 4-6 mg cigarettes with percentage of vents blocked (Figure 6). There was no significant effect on the 7-12 mg cigarettes. Similar decreases were also observed for puff number $(90 \%$ significance for $1-3$ $\mathrm{mg}$ and 4-6 mg 'tar' cigarettes). There was no significant effect of $50 \%$ or $100 \%$ vent blocking on mean puff duration for any of the cigarette categories. Thus, when the experimenter artificially blocks the ventilation zone, the smoker adjusts by reducing the puff volume and puff number, at least for cigarettes in the 1-3 and 4-6 mg 'tar' categories.

ZACNY et al. (61) made a similar observation with $1 \mathrm{mg}$ 'tar' cigarettes (FTC method) smoked by five subjects who normally smoked medium to high 'tar' yield brands (average 'tar' of regular brands, $15.7 \mathrm{mg}$ ). Their results are shown in Table 7 and the authors suggested that the reduction in puff volume with vent blocking was due to 

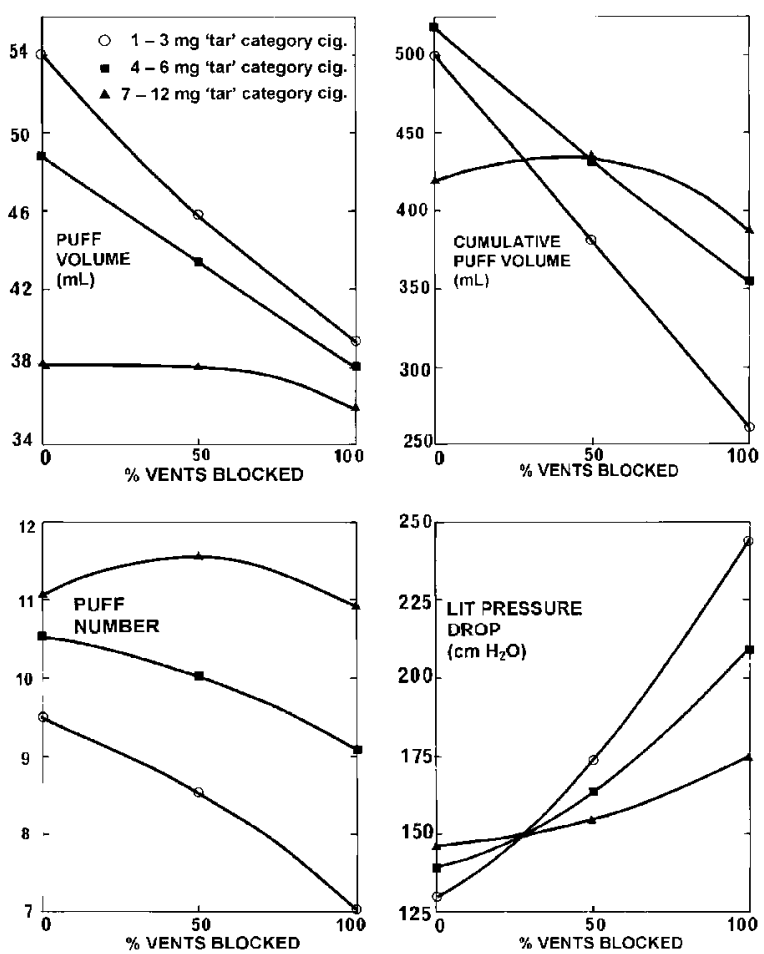

Figure 6.

Effect of deliberately blocking vent zone on mean puffing behavior of smokers (REEVES et al., 1997 [41])

the increases in draw resistance of the cigarette experienced by the smoker as the filter was systematically blocked. REEVES et al. (41) also measured the pressure drops of the lit cigarettes and concluded that changes in pressure characteristics were primarily responsible for the puff volume reductions with partial or complete vent zone coverage (Figure 6).

In the study of REEVES and co-workers, the nicotine and 'tar' measured on the filter portion of the cigarette butts were converted to estimated yields of nicotine and 'tar' available to the smoker, as reported by AYYA et al. (1) and ST. CHARLES and HILTON (47). This was done using the filtration efficiencies $(\theta, \%)$ of the filter for nicotine and 'tar':

$$
\begin{aligned}
\theta & =\frac{S_{1}-S_{2}}{S_{1}} \cdot 100 \\
& =\frac{\Delta S}{S_{2}+\Delta S} \cdot 100
\end{aligned}
$$

where

$S_{1}$ is the amount of smoke component (nicotine or ' ${ }^{2} a r^{\prime}$ ) input to the filter during smoking,

$S_{2}$ is the amount of smoke component exiting the filter during smoking, i.e. the yield available to the smoker and

$\Delta S$ is the amount of smoke component retained on the filter during smoking, $=S_{1}-S_{2}$.
Table 7.

Effect of deliberately blocking vent zone on mean puffing behavior of smokers, ZACNY et al., $1986(61)^{\mathrm{a}}$

\begin{tabular}{l|r|r|r|c}
\hline \multirow{2}{*}{$\begin{array}{l}\text { Parameter } \\
\text { measured }\end{array}$} & \multicolumn{3}{|c|}{$\%$ Vents blocked } & $\begin{array}{c}\text { Significance } \\
\text { of differ. (\%) }\end{array}$ \\
\cline { 2 - 4 } & 0 & 50 & 100 & \\
\hline $\begin{array}{l}\text { Puff volume (mL) } \\
\text { Puff duration (s) }\end{array}$ & 63.3 & 54.8 & 42.8 & 99 \\
& 1.9 & 1.8 & $\begin{array}{c}\text { No sig. } \\
\text { difference }\end{array}$ \\
$\begin{array}{l}\text { Puff number } \\
\text { Interpuff interv. (s) }\end{array}$ & 13.2 & 11.1 & 9.2 & 99 \\
& 20.6 & 22.1 & 23.3 & 95 \\
\hline
\end{tabular}

aFive subjects whose regular brands were high 'tar'. In this experiment, each subject smoked a $1 \mathrm{mg}$ 'tar' cigarette with the three vent block conditions on 5 consecutive days.

ST. CHARLES and HILTON (47) determined nicotine and 'tar' filtration efficiencies $\left(\theta_{\text {nicotine }}\right.$ and $\left.\theta_{\text {tar }}\right)$ for the filters on each of the 26 cigarette brands used by REEVES and coworkers, at a variety of smoking regimes and at different levels of filter ventilation zone blockage. The nicotine and 'tar' filtration efficiencies decreased with puffing velocity, as observed in other studies $(12,14,32,37)$. Using estimates of the flow velocities from the behavioral experiments and the amounts of nicotine and 'tar' measured on the filters $\left(\Delta S_{\text {nicotine }}\right.$ and $\left.\Delta S_{\text {tar }}\right)$, ST. CHARLES and HILTON (47) calculated the yields of nicotine and 'tar' available to the smokers ( $S_{2 \text { nicotune }}$ and $S_{2 \text { tar }}$ ) using the above equation.

The estimated mean yields and standard deviations determined during the behavioral experiments at the three vent blocking conditions $(0 \%, 50 \%$ and $100 \%$ blocked) as well as the "free" laboratory and home smokings are shown in Tables 8 and 9. The estimated nicotine yields were shown to be more accurate than the ' $t a r$ ' yields because variation of filtration efficiencies with flow velocity is lower for nicotine than 'tar' at higher velocities (47). Hence, estimates of the flow velocity for the behavioral experiments are less critical for the nicotine data. Results for the effect of vent blocking on nicotine and 'tar' yields determined during standard machine smoking conditions are also shown in Tables 8 and 9.

The results in Tables 8 and 9 show that with vent zones deliberately blocked by the experimenter, human smoking has less effect on mean nicotine and 'tar' yield than does standard machine smoking. Indeed, there is no significant difference in mean nicotine yields to the smoker by $50 \%$ and $100 \%$ blocking of the ventilation zone in any of the three 'tar' categories (Table 8). The relatively small increases in mean 'tar' yields to the smoker with vent blockage are significant at the $99 \%$ level for the 1-3 and 4-6 mg 'tar' categories (Table 9). It is likely that the changes in human puffing parameters (puff volume and puff numbers) produced by deliberately 
Table 8.

Estimated mean nicotine yields (standard deviation), mg, of the smokers (study of REEVES and co-workers, reported by St. CharLes and HiLton[47])

\begin{tabular}{l|cccc}
\hline \multirow{2}{*}{ Smoking conditions } & \multicolumn{3}{|c}{ FTC 'tar' category } \\
\cline { 2 - 4 } & $1-3 \mathrm{mg}$ & $4-6 \mathrm{mg}$ & $7-12 \mathrm{mg}$ \\
\hline \multirow{2}{*}{ Unblocked - } & 0.46 & 0.59 & 0.68 \\
human smoking & $(0.34)$ & $(0.29)$ & $(0.26)$ \\
$50 \%$ Blocked - & 0.57 & 0.60 & 0.77 \\
human smoking & $(0.36)$ & $(0.20)$ & $(0.37)$ \\
100\% Blocked - & 0.55 & 0.56 & 0.78 \\
human smoking & $(0.28)$ & $(0.20)$ & $(0.39)$ \\
Laboratory $_{\text {ffree" smoking }}$ & 0.51 & 0.57 & 0.74 \\
Home smoking & $0.22)$ & $(0.17)$ & $(0.20)$ \\
& 0.57 & 0.53 & 0.75 \\
Number of subjects & $0.20)$ & $(0.13)$ & $(0.21)$ \\
Unblocked - & 9 & 20 & 19 \\
machine smoking & & & \\
50\% Blocked - & 0.14 & 0.45 & 0.72 \\
machine smoking & & & \\
100\% Blocked - & 0.28 & 0.62 & 0.79 \\
machine smoking & & & \\
\hline
\end{tabular}

a35 mL, 2 s puff once per minute.

blocking the ventilation zone account for these differ ences between the human and machine derived smoke yields.

It is also clear from the results in Tables 8 and 9 that the estimated mean nicotine and 'tar' yields available to the smokers under "free" laboratory and home smoking conditions are generally in the order of the cigarette 'tar' category: (1-3 mg cigarette) < (4-6 mg cigarette) $<(7-12$ $\mathrm{mg}$ cigarette). This order is significant at the $99.9 \%$ level for both nicotine and 'tar'.

All of the information given in Tables 8 and 9 is mean yield data, i.e., the mean of the subjects and brands in a given FTC 'tar' category. The human smoking data for each cigarette brand are also of interest and are presented in Figure 7 using the individual data from the study of REEVES and co-workers as calculated by ST. CHARLES (46). The plots show the effect of blocking $50 \%$ and $100 \%$ of the filter vents on the relative increases in nicotine and 'tar' yields as a function of the original filter ventilation of the cigarette when bumans smoke the cigarettes. These plots are directly comparable to those in Figure 5 with the cigarettes smoked by machine. As discussed above, the estimated nicotine yields are more accurate than the estimated 'tar' yields. Three conclusions can be drawn.

1. When the experimenter deliberately blocks the vent zone, the relative increase in yield of a given smoke component is much less under human smoking conditions than when the cigarette is smoked by
Table 9.

Estimated mean 'tar' yields (standard deviation), mg, of the smokers (study of REEVES and co-workers, reported by St. ChARLES and HILTON [47])

\begin{tabular}{|c|c|c|c|}
\hline \multirow{2}{*}{ Smoking conditions } & \multicolumn{3}{|c|}{ FTC 'tar' category } \\
\hline & $1-3 \mathrm{mg}$ & $4-6 \mathrm{mg}$ & $7-12 \mathrm{mg}$ \\
\hline $\begin{array}{l}\text { Unblocked - } \\
\text { human smoking }\end{array}$ & $\begin{array}{c}4.2 \\
(2.6)\end{array}$ & $\begin{array}{c}7.2 \\
(4.4)\end{array}$ & $\begin{array}{l}10.1 \\
(5.1)\end{array}$ \\
\hline $\begin{array}{l}50 \% \text { Blocked - } \\
\text { human smoking }\end{array}$ & $\begin{array}{c}6.4 \\
(4.3)\end{array}$ & $\begin{array}{c}8.8 \\
(4.8)\end{array}$ & $\begin{array}{l}10.5 \\
(5.3)\end{array}$ \\
\hline $\begin{array}{l}100 \% \text { Blocked - } \\
\text { human smoking }\end{array}$ & $\begin{array}{l}9.0 \\
(6.1)\end{array}$ & $\begin{array}{c}9.6 \\
(4.3)\end{array}$ & $\begin{array}{l}10.3 \\
(5.4)\end{array}$ \\
\hline $\begin{array}{l}\text { Laboratory } \\
\text { "free" smoking }\end{array}$ & $\begin{array}{c}5.2 \\
(3.1)\end{array}$ & $\begin{array}{c}7.6 \\
(2.3)\end{array}$ & $\begin{array}{l}9.9 \\
(2.8)\end{array}$ \\
\hline Home smoking & $\begin{array}{c}6.4 \\
(2.8)\end{array}$ & $\begin{array}{c}7.1 \\
(1.6)\end{array}$ & $\begin{array}{l}10.2 \\
(3.0)\end{array}$ \\
\hline Number of subjects & 9 & 20 & 19 \\
\hline $\begin{array}{l}\text { Unblocked - } \\
\text { machine smoking }\end{array}$ & 1.4 & 5.2 & 9.6 \\
\hline $\begin{array}{l}50 \% \text { Blocked - } \\
\text { machine smoking }\end{array}$ & 3.1 & 8.1 & 11.2 \\
\hline $\begin{array}{l}100 \% \text { Blocked - } \\
\text { machine smoking }\end{array}$ & 7.5 & 11.5 & 12.6 \\
\hline
\end{tabular}

${ }^{\text {a } 35 ~} \mathrm{~mL}, 2 \mathrm{~s}$ puff once per minute.

machine. In fact, for about a third of the brands depicted in Figure 7a) and 7b), blocking the vents resulted in the humans apparently obtaining less nicotine from the cigarette than with the unblocked condition, i.e., nicotine/nicotine $<1$. In practice, within the variability of a given smoker, there is little real difference in any of the data points in Figure 7.

2. Under buman smoking conditions the increases in yield/yield as the filter ventilation level increases are much smaller than is observed under machine smoking conditions ( $c f$. Figures 5 and 7 ).

3. For a given cigarette, the effect of degree of vent blocking on yields under human smoking conditions is in the order ' $t a r$ ' > nicotine, as is observed under machine smoking conditions.

The "CO boost" data of SWEENEY et al. (56) for human ad libitum smoking are also shown in Figure 7(c). In using the data in Figure 7(c) it is assumed that the lip blocking condition of SWEENEY et al. covers about 50\% of the ventilation zone, as concluded in an earlier study (27). The blocked "CO boost" results do increase systematically with vent blockage at unlit filter ventilations above about $60 \%$. These increases are within the overall variation of the $\operatorname{tar} / \operatorname{tar}_{0}$ data of ST. CHARLES. Given the somewhat similar overall objectives but quite different experimental protocols and techniques for estimating smoke yields in the studies of REEVES and co-workers and SWEENEY et al., the two sets of results are remarkably consistent. 

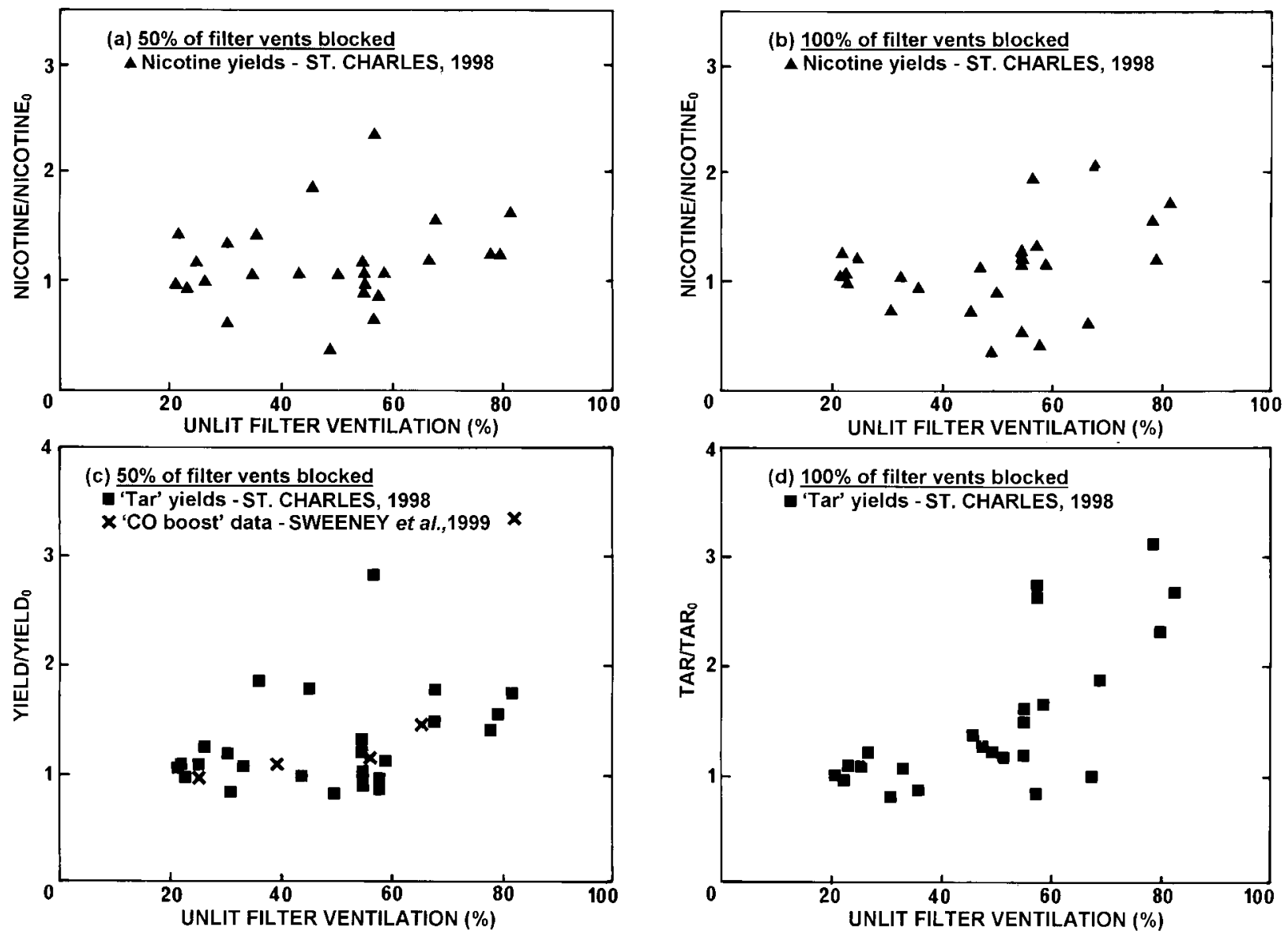

Figure 7.

Ad libitum human smoking - effect of filter ventilation on relative increase in yields when filter vent zone is deliberately blocked

When referring to cigarette brands with filter ventilation levels below 56\%, SWEENEY et al. (56) stated

[w]e have no explanation for this discrepancy between the effects of vent blocking for human smokers vs. smoking machines.

Based on the data of REEVES et al. (41) and ZACNY et al. (61), presented in this section of the review, the explanation is simple: when the experimenter deliberately blocks the ventilation zone, human smokers adjust by taking fewer and smaller puffs. Clearly, smoking machines cannot do this. It seems reasonable to assume that this adjustment would also occur when humans inadvertedly block the vents during smoking.

\section{SECTION 4.}

\section{SIMULTANEOUS DETERMINATION OF}

INCIDENCE OF VENT BLOCKING AND SMOKE YIELDS UNDER $A D$ LIBITUM HUMAN SMOKING CONDITIONS

The incidence of vent blocking among smokers, as discussed in Section 1, is of interest but its significance is limited without measuring its effect on human smoke yields. The effect of vent blocking on machine smoke yields, as discussed in Section 2, is of academic interest. In terms of human smoking it is almost irrelevant because humans do not smoke like machines with a constant and regular puffing regimen.

The effect of deliberate vent blocking by the experimenter indicates that humans change their smoking behavior to adjust for the artificial blocking of the vents as discussed in Section 3, primarily as a response to the change in cigarette pressure drop. Presumably the subjects would also make this adjustment if they themselves inadvertedly blocked the vents during their normal smoking.

The most meaningful way to determine the significance of vent blocking on the smoke yields available to the smoker is to measure the incidence of vent blocking and effect on smoke yields at the same time, with the subjects smoking their usual brand of cigarette in their normal day-to-day environment. Given that experimental conditions are known to perturb smoking behavior $(8,36,57)$, a non-invasive means of observing the incidence of vent blocking and measuring smoke yields is desirable.

Such a study has been undertaken in the UK (6). The ninhydrin technique was used to visualize saliva stains on cigarette butts and facilitate maximum mouth insertion 
Table 10

Estimated mean nicotine yields to the smokers, BAKER et al., 1998 (6)

\begin{tabular}{|c|c|c|c|}
\hline Cigarette & Std. & Light & $\begin{array}{l}\text { Ultra } \\
\text { Light }\end{array}$ \\
\hline Machine yield ${ }^{\mathrm{a}}(\mathrm{mg})$ & 1.10 & 0.89 & 0.35 \\
\hline $\begin{array}{l}\text { Mean yield to the } \\
\text { smokers (mg) }\end{array}$ & 0.87 & 0.71 & 0.45 \\
\hline Standard deviation & 0.27 & 0.20 & 0.14 \\
\hline $\begin{array}{l}\text { Standard deviation/mean } \\
\text { yield to the smokers }\end{array}$ & 0.31 & 0.28 & 0.31 \\
\hline Number of subjects & 204 & 197 & 195 \\
\hline
\end{tabular}

a35 mL, $2 \mathrm{~s}$ puff once per minute.

depth measurements. This aspect of the study has been discussed in Section 1.4 above and a summary of the results is included in Tables 3 and 4 . In addition, the subjects themselves collected their cigarette filter butts, and those filters were analyzed to provide additional information on smoke yields. Three filter cigarette brands were used, designated as Standard (non-ventilated filter, $12 \mathrm{mg}$ 'tar', $1.1 \mathrm{mg}$ nicotine), Light (29\% ventilated filter, $9.3 \mathrm{mg}$ 'tar', $0.89 \mathrm{mg}$ nicotine) and Ultra Light (56\% ventilated filter, $4.1 \mathrm{mg}$ 'tar', $0.35 \mathrm{mg}$ nicotine). One pack of twenty cigarettes of the designated brand was given to 300 smokers of that brand. Each subject smoked the cigarettes in their normal way during their day-to-day activities and collected the filter butts after smoking. Approximately $80 \%$ of the subjects returned the filter butts. Estimates of nicotine yields available to the smokers were calculated from the amount of nicotine trapped on the filter using mean nicotine filtration efficiencies, as described in Section 3. The mean nicotine yields are shown in Table 10. They are in the order of the cigarette yield category: Standard > Light > Ultra Light. Based on these data, it appears that the range of nicotine yields which humans can obtain from a given cigarette, relative to the mean nicotine, is independent of whether the cigarette is ventilated or non-ventilated.

In Figure 8, the estimated nicotine yields to the smokers are compared to mean mouth insertion depths to see what effect vent zone coverage has on yields. At a given mouth insertion depth, there is a large variation in nicotine yield to the smoker due to differences in the way subjects smoke cigarettes. The position of the start of the ventilation zone is also indicated in Figure 8. This separates those smokers whose mouth insertion depths are too short to cover any of the vent zone from those who cover at least part of the zone with their lips. It is clear that there is no noticeable difference in nicotine yields or distributions on either side of the vent zone position for either of the filter ventilated cigarettes. Thus, (a) Light cigarette

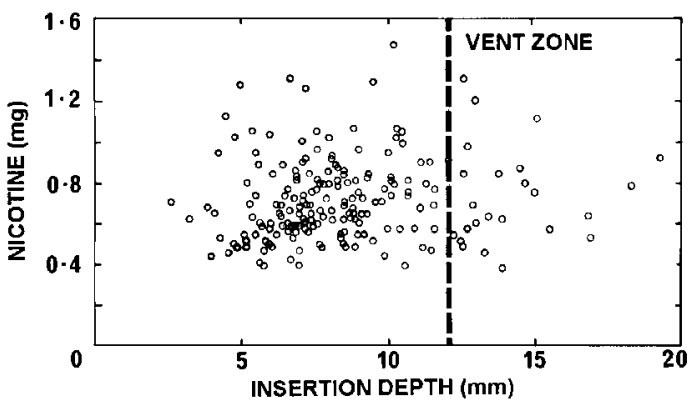

(b) Ultra Light cigarette

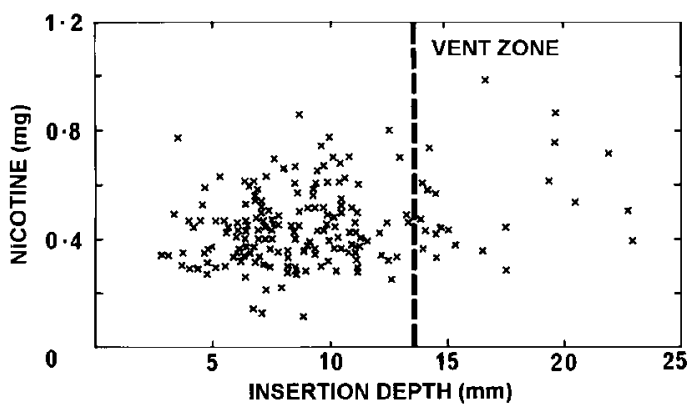

Figure 8.

Estimated nicotine yields and insertion depths (Baker et al.,1998)

taken as a whole, this study has shown that coverage of the filter vent zone of a given cigarette by lips as it occurs in practice has a only relatively minor effect on nicotine yields, if any, compared to other smoker behavior factors such as puff volume, frequency and number.

\section{CONCLUSIONS}

1. The occurrence of ventilation zone blocking as it occurs in practice among smokers has only a relatively minor effect on human smoke yields compared to other smoker behavior factors.

2. When the filter ventilation zone is blocked during smoking, either partially or completely, the smoker adjusts by taking smaller puffs and fewer of them. The yield of smoke components to the smoker is consequently much nearer to that with the unblocked filter than is observed with a smoking machine.

3. Because of these changes in puffing behavior during human smoking, predictions of the effects of filter vent blocking on smoke yields based solely on smoking machine yields are deceptive.

4. The incidence of vent zone blocking by fingers during smoking is small - only $4 \%$ of smokers have their fingers in contact with the cigarette during all puffs, and even then the contact is not necessarily with the ventilation zone. 
5. Estimates of the incidence of vent zone blocking by lips range from $15-24 \%$ of smokers (saliva-staining technique) to $50 \%$ of smokers ('tar' staining pattern technique). Although both techniques are subject to uncertainties, the saliva-staining technique is a more direct observational method and is likely to be the more reliable.

6. For those smokers who do block the vents with their lips during smoking, the maximum coverage of the vents is about $50 \%$ for most "blockers", with a mean coverage of $27 \%$.

\section{Acknowledgments:}

We would like to thank the following colleagues for making many helpful comments and suggestions on various aspects of this review during its preparation: Paul Case, Mike Dixon, Evan Gregg, Véronique Marchand, Kevin McAdam, Helmut Reif, John Robinson, Wolfram Röper, Neil Sinclair, Kelley St. Charles and David Townsend.

\section{REFERENCES}

1. Ayya, N., D. Hilton, F.K. St. Charles, N. Reeves, and M. Dixon: Measurement of puffing behavior in lights and ultra light smokers with ventilation holes partially and fully blocked; Paper presented at $51^{\text {st }}$ Tobacco Chemists' Research Conference, WinstonSalem, NC, U.S.A, Program Booklet and Abstracts, no. 14, p. 31, 1997.

2. Baker, R.R. and R.A. Crellin: The diffusion of carbon monoxide out of cigarettes; Beitr. Tabakforsch. Int. 9 (1977) 131-140.

3. Baker, R.R.: The effect of ventilation on cigarette combustion mechanisms; Rec. Adv. Tob. Sci. 10 (1984) 88-150.

4. Baker, R.R.: The viscous and inertial flow of air through perforated papers; Beitr. Tabakforsch. Int. 14 (1989) 253-260.

5. Baker, R.R. and L.S. Lewis: Filter ventilation - has there been a "cover-up"?; Rec. Adv. Tob. Sci. 23 (1997) 152-196.

6. Baker, R.R., M. Dixon, and C.A. Hill: The incidence and consequences of filter vent blocking amongst British smokers; Beitr. Tabakforsch. Int. 18 (1998) 71-83.

7. Barkemeyer, H., W. Schulz, and F. Seehofer, British American Tobacco, Germany, unpublished results, 1984.

8. Comer, A.K. and D.E. Creighton: The effect of experimental conditions on smoking behaviour; in: Smoking behaviour: physiological and psychological influences, edited by R.E. Thornton, Churchill Livingstone, London, 1978, pp. 76-88.

9. Creighton, D.E., M.J. Nobel, and R.T. Whewell: Instruments to measure, record and duplicate human smoking patterns; in: Smoking behaviour: physiological and psychological influences, edited by R.E. Thornton, Churchill Livingstone, London, 1978, pp. 277-288.

10. Darrall, K.G.: Smoking machine parameters and cigarette smoke yields; Sci. Total Env. 74 (1988) 263-278.

11. Djordjevic, M.V., S.D. Stellman, and E. Zang: Doses of nicotine and lung carcinogens delivered to cigarette smokers; J. Natl. Canc. Inst. 92 (2000) 106-111.

12. Dwyer, R.W. and S.G. Abel: The efficiencies of cellulose acetate filters; Beitr. Tabakforsch. Int. 13 (1986) 243-253.

13. Dwyer, R.W., K.A. Cox, and J.E. Bickett: Sources of pressure-drop and ventilation variability in cigarettes; Rec. Adv. Tob. Sci. 13 (1986) 82-118.

14. Eaker, D.W.: Dynamic behavior and filtration of mainstream smoke in the tobacco column and filter; Rec. Adv. Tob. Sci. 16 (1990) 103-187.

15. Ferris, R.P.: British American Tobacco, UK, unpublished results, 1983.

16. Guyatt, A.R., A.J.T. Kirkham, D.C. Mariner and G. Cumming: Is alveolar carbon monoxide an unreliable index of carboxyhaemoglobin changes during smoking in man?; Clin. Sci. 74 (1988) 29-36.

17. Helms, A.: The concentration of tar, nicotine and carbon monoxide in the smoke of ventilated filter cigarettes: Comparisons of different types of filter ventilations; Presented at CORESTA Smoke Study Group Meeting, Florence, Italy, 1983.

18. Helms, A.: Influence of laser perforation of cigarette filters on the smoke composition: Influence of the depth of holes; Presented at CORESTA Congress, Vienna, Austria, 1984.

19. Hill, C.A.: Imperial Tobacco, UK, unpublished results, 1983.

20. Kozlowski, L.T., R.C. Frecker, V. Khouw, and M.A. Pope: The misuse of "less-hazardous" cigarettes and its detection: Hole-blocking of ventilated filters; Amer. J. Pub. Health 70 (11) (1980) 1202-1203.

21. Kozlowski, L.T., W.S. Rickert, M.A. Pope, J.C. Robinson, and R.C. Frecker: Estimating the yield to smokers of tar, nicotine, and carbon monoxide from the "lowest yield" ventilated filter-cigarettes; Br. J. Addict. 77 (1982) 159-165.

22. Kozlowski, L.T., M.A. Pope, and J.E. Lux: Prevalence of the misues of ultra-low-tar cigarettes by blocking filter vents; Am. J. Pub. Health 6 (1988) 694-695.

23. Kozlowski, L.T., T.F. Heatherton, R.C. Frecker and H.E. Nolte: Self-selected blocking of vents on lowyield cigarettes; Pharmacol. Biochem. Behav. 33 (1989) 815-819.

24. Kozlowski, L.T. and J.L. Pillitteri: Vent-blocking of vented filter cigarettes: 1979 to 1994. Handout for National Cancer Institute Conference: The FTC cigarette test method for determining tar, nicotine, and carbon monoxide yields of U.S. cigarettes; 1994. 
25. Kozlowski, L.T., J.L. Pillitteri and C.T. Sweeney: Misuse of "light" cigarettes by means of vent blocking; J. Subst. Abuse 6 (1994) 333-336.

26. Kozlowski, L.T., M.E. Goldberg, B.A. Yost, F.M. Ahern, K.R. Aronson and C.T. Sweeney: Smokers are unaware of the filter vents now on most cigarettes: Results of a national survey; Tob. Control 5 (1996) 265-270.

27. Kozlowski, L.T., C.T. Sweeney and J.L. Pillitteri: Blocking cigarette filter vents with lips more than doubles carbon monoxide intake from ultra-low tar cigarettes; Exper. Clin. Psychopharmacol. 4 (1996) 404-408.

28. Kozlowski, L.T. and C.T. Sweeney: Low-yield, light, and ultra-light cigarettes: Let's understand the product before we promote; in: Social marketing: theoretical and practical perspectives, edited by M.E. Goldberg, M. Fishbein and S. Middlestedt, Erlbaum Associates, Mahwah, New Jersey, U.S.A., pp. 231-244.

29. Kozlowski, L.T., E.L. White, C.T. Sweeney, B.A. Yost, F.M. Ahern, and M.E. Goldberg: Few smokers know their cigarettes have filter vents; Am. J. Pub. Health 88 (1998) 681-682.

30. Lewis, L.S. R.J. Reynolds Tobacco Company, U.S.A., unpublished results, 1995.

31. Lombardo, T., C.J. Davis and D.M. Prue: When low tar cigarettes yield high tar: cigarette filter ventilation hole blocking and its detection; Addict. Behav. 8 (1983) 67-69.

32. Mathis, D.E.: Filtration efficiency in ventilated cigarettes; Paper presented at $36^{\text {th }}$ Tobacco Chemists' Research Conference, Raleigh, NC, U.S.A., Program Booklet and Abstracts, no. 29, p. 16, 1982.

33. Mathis, D.E.: Flow rate dependence of ventilation; Beitr. Tabakforsch. Int. 14 (1987) 11-19.

34. Mattina, C.F. and W.A. Selke: Influence of the paper on the smoke of cigarettes; Proc. $173^{\text {rd }}$ Amer. Chem. Soc. Symp., Recent Advances in the Chemical Composition of Tobacco and Tobacco Smoke, 1977, pp. 533-552.

35. McBride, C., Imperial Tobacco, Canada, unpublished results, 1984.

36. Ossip-Klein, D.J., J.E. Martin, B.D. Lomax, D.M. Prue, and C.J. Davis: Assessment of smoking topography generalization across laboratory, clinical and naturalistic settings; Addictive Behaviours 8 (1983) 11-17.

37. Overton, J.R.: Filtration of cigarette smoke: relative contributions of inertial impaction, diffusional deposition and direct interception; Beitr. Tabakforsch. 7 (1973) 117-120.

38. Owens Jr., W.F.: Effects of cigarette paper on smoke yield and composition; Rec. Adv. Tob. Sci. 4 (1978) 3-34.

39. Pillitteri, J.L., A.C. Morse, and L.T. Kozlowski: Detection of vent-blocking on light and ultralight cigarettes; Parmacol. Biochem. Behav. 48 (1994)
$539-542$

40. Porter, A. and P.J. Dunn: Mouth insertion depths in Canadian smokers; Beitr. Tabakforsch. Int. 18 (1998) 85-91.

41. Reeves, N., M. Dixon, N. Ayya, D. Hilton, and F.K. St. Charles: Measurement of puffing behaviour in lights and ultra light smokers with ventilation holes partially and fully blocked; Proceedings of the CORESTA Smoke and Technology Groups Meeting, Hamburg, Germany, 1997, pp. 62-70.

42. Reif, H.: Mathematical treatment of ventilation parameters; Beitr. Tabakforsch. Int. 11 (1982) 209-218.

43. Rickert, W.S., J.C. Robinson, J.C. Young, N.E. Collishaw, and D.F. Bray: A comparison of the yields of tar, nicotine, and carbon monoxide of 36 brands of Canadian cigarettes tested under three conditions; Prev. Med. 12 (1983) 682-694.

44. Robinson, D.P., British American Tobacco, U.K., unpublished results, 1985.

45. Röper, W., Reemtsma, Germany, unpublished results, 1997.

46. St. Charles, F.K.: Brown \& Williamson Tobacco Corporation, U.S.A., unpublished data (1998) from the study of Reeves et al.,1997 (Reference 41).

47. St. Charles, F.K. and D.C. Hilton: Estimation of consumer-smoked cigarette yields from filter analytical data; Paper presented at $52^{\text {nd }}$ Tobacco Science Research Conference, Atlanta, GA, U.S.A., Program Booklet and Abstracts, no. 45, p. 36, 1998.

48. Scherer, G.: Smoking behaviour and compensation: a review of the literature; Psychopharm. 145 (1999) 1-20.

49. Schneider, W., A. Schlüter, and F. Seehofer: The effects of the properties of materials in a cigarette on filter ventilation; Beitr. Tabakforsch. Int. 12 (1984) 123-136.

50. Schneider, W.: Effects of occlusion of ventilation zones on tar yields; Proceedings of the CORESTA Smoke and Technology Groups Meeting, Hamburg, Germany, 1997, 71-78.

51. Schulz, W., British American Tobacco, Germany, unpublished results, 1997.

52. Selke, W.A. and J.H. Matthews: The permeability of cigarette papers and cigarette ventilation; Beitr. Tabakforsch. Int. 9 (1978) 193-200.

53. Shibata, M., E. Takase, T. Matsumoto, and M. Sasaki: Study of cross sectional smoke distribution in cigarette filters; Collection of the Smoke and Technology Group Papers at the CORESTA Congress, Yokohama, Japan, 1996, pp. 69-77.

54. Shopland, D. (ed.): The FTC cigarette test method for determining tar, nicotine, and carbon monoxide yields of U.S. cigarettes; Report of the N.C.I. Expert Committee, 1996.

55. Sweeney, C.T. and L.T. Kozlowski: Blocking filter vents increases carbon monoxide levels from ultralight, but not light cigarettes; Pharmacol. Biochem. 
Behav. 59 (1998) 767-773.

56. Sweeney, C.T, L.T. Kozlowski, and P. Parsa: Effect of filter vent blocking on carbon monoxide exposure from selected lower tar cigarette brands; Pharmacol. Biochem. Behav. 63 (1999) 167-173.

57. Tobin, M.J. and M.A. Sackner: Monitoring smoking patterns of low and high tar cigarettes with inductive plethysmography; Amer. Rev. Resp. Dis. 126 (1982) 258-264.

58. U.S. Food and Drug Administration: Nicotine in cigarettes and smokeless tobacco products is a drug and these products are nicotine delivery devices under the Federal Food, Drug and Cosmetic Act (Jurisdictional Analysis). 60 Federal Register (1995) $41,545-41,787$ at $41,717-718$.

59. Wiethaup, W., British American Tobacco, Germany, unpublished results, 1984.

60. Woodman, G., D.M. Wintoniuk, R.G. Taylor, and S.W. Clarke: Time course of end-expired carbon monoxide concentration is important in studies of cigarette smoking; Clin. Sci. 73 (1987) 553-555.

61. Zacny, J.P., M.L. Stitzer, and J.E. Yingling: Cigarette filter vent blocking: Effects on smoking topography and carbon monoxide exposure; Pharmacol. Biochem. Behav. 25 (1986) 1245-1252.
62. Zacny, J.P. and M.L. Stitzer: Cigarette brand-switching: effects on smoke exposure and smoking behavior; J. Pharmacol. Exper. Ther. 246 (1988) 619-627.

Addresses for correspondence

Richard R. Baker

British American Tobacco

$R$ ED Centre

Regents Park Road, Millbrook

Southampton, SO15 8TL

UK

and

Leslie S. Lewis

R.J. Reynolds Tobacco Company

Research and Development

P.O. Box 1487

Winston-Salem

NC 27102-1487

USA 